\title{
Next-generation angular distribution models for top-of-atmosphere radiative flux calculation from CERES instruments: methodology
}

\author{
W. Su ${ }^{1}$, J. Corbett ${ }^{2}$, Z. Eitzen ${ }^{2}$, and L. Liang ${ }^{2}$ \\ ${ }^{1}$ MS420, NASA Langley Research Center, Hampton, Virginia, USA \\ ${ }^{2}$ Science Systems \& Applications, Inc., Hampton, Virginia, USA \\ Correspondence to: W. Su (wenying.su-1@ nasa.gov)
}

Received: 20 June 2014 - Published in Atmos. Meas. Tech. Discuss.: 27 August 2014

Revised: 22 December 2014 - Accepted: 7 January 2015 - Published: 5 February 2015

\begin{abstract}
The top-of-atmosphere (TOA) radiative fluxes are critical components to advancing our understanding of the Earth's radiative energy balance, radiative effects of clouds and aerosols, and climate feedback. The Clouds and the Earth's Radiant Energy System (CERES) instruments provide broadband shortwave and longwave radiance measurements. These radiances are converted to fluxes by using scene-type-dependent angular distribution models (ADMs). This paper describes the next-generation ADMs that are developed for Terra and Aqua using all available CERES rotating azimuth plane radiance measurements. Coincident cloud and aerosol retrievals, and radiance measurements from the Moderate Resolution Imaging Spectroradiometer (MODIS), and meteorological parameters from Goddard Earth Observing System (GEOS) data assimilation version 5.4.1 are used to define scene type. CERES radiance measurements are stratified by scene type and by other parameters that are important for determining the anisotropy of the given scene type. Anisotropic factors are then defined either for discrete intervals of relevant parameters or as a continuous functions of combined parameters, depending on the scene type. Significant differences between the ADMs described in this paper and the existing ADMs are over clear-sky scene types and polar scene types. Over clear ocean, we developed a set of shortwave (SW) ADMs that explicitly account for aerosols. Over clear land, the SW ADMs are developed for every $1^{\circ}$ latitude $\times 1^{\circ}$ longitude region for every calendar month using a kernel-based bidirectional reflectance model. Over clear Antarctic scenes, SW ADMs are developed by accounting the effects of sastrugi on anisotropy. Over sea ice, a sea-ice brightness index is used to classify the scene type. Under cloudy conditions over all surface types, the longwave (LW)
\end{abstract}

and window (WN) ADMs are developed by combining surface and cloud-top temperature, surface and cloud emissivity, cloud fraction, and precipitable water. Compared to the existing ADMs, the new ADMs change the monthly mean instantaneous fluxes by up to $5 \mathrm{~W} \mathrm{~m}^{-2}$ on a regional scale of $1^{\circ}$ latitude $\times 1^{\circ}$ longitude, but the flux changes are less than $0.5 \mathrm{~W} \mathrm{~m}^{-2}$ on a global scale.

\section{Introduction}

The Clouds and the Earth's Radiant Energy System (CERES) project has been providing data products critical to advancing our understanding of the effects of clouds and aerosols on radiative energy within the Earth-atmosphere system. CERES data are used by the science community to study the Earth's energy balance (e.g., Trenberth et al., 2009; Kato et al., 2011; Loeb et al., 2012; Stephens et al., 2012), aerosol direct radiative effects (e.g., Satheesh and Ramanathan, 2000; Zhang et al., 2005; Loeb and Manalo-Smith, 2005; Su et al., 2013), aerosol-cloud interactions (Loeb and Schuster, 2008; Quaas et al., 2008; Su et al., 2010b), and to evaluate global general circulation models (e.g., Pincus et al., 2008; Su et al., 2010a; Wang and Su, 2013; Wild et al., 2013).

The CERES instrument consists of a three-channel broadband scanning radiometer (Wielicki et al., 1996). The scanning radiometer measures radiances in shortwave $(\mathrm{SW}, 0.3-$ $5 \mu \mathrm{m}$ ), window (WN, 8-12 $\mu \mathrm{m}$ ), and total $(0.3-200 \mu \mathrm{m})$ channels at a spatial resolution of $\sim 20 \mathrm{~km}$ at nadir. The longwave (LW) component is derived as the difference between total and SW channels. These measured radiances at a given SunEarth-satellite geometry are converted to outgoing reflected 
solar and emitted thermal top-of-atmosphere (TOA) radiative fluxes. To do so, we must account for the angular distribution of the radiance field, which is scene type dependent. Here scene type is a combination of variables (e.g., surface type, cloud fraction, cloud optical depth, cloud phase, aerosol optical depth, precipitable water, lapse rate) that we use to group the data to develop distinct angular distribution models (ADMs). To facilitate the construction of ADMs, there are pairs of identical CERES instruments on both Terra and Aqua spacecrafts. At the beginning of these missions one of the instruments on each spacecraft was always placed in a rotating azimuth plane (RAP) scan mode. In this mode, the instrument scans in elevation as it rotates in azimuth, thus acquiring radiance measurements from a wide range of viewing combinations. To provide accurate scene type information within CERES footprints, imager (Moderate Resolution Imaging Spectroradiometer (MODIS) on Terra and Aqua) cloud and aerosol retrievals are averaged over CERES footprints by accounting for the CERES point spread function (PSF; Smith, 1994) and are used for scene type classification.

The first set of CERES ADMs was developed using 9 months of CERES and Visible Infrared Scanner (VIRS) data from the Tropical Rainfall Measuring Mission (TRMM) satellite (Loeb et al., 2003). This set of ADMs represents a more improved anisotropy characterization than the ADMs used for Earth Radiation Budget Experiment (ERBE), which only provided anisotropy for 12 scene types (Smith et al., 1986; Suttles et al., 1988). Because TRMM is in a $350 \mathrm{~km}$ circular precessing orbit with a $35^{\circ}$ inclination angle, CERES TRMM sampled the full range of solar zenith angle over regions between $38^{\circ} \mathrm{S}$ and $38^{\circ} \mathrm{N}$ every 46 days.

The second set of CERES ADMs was developed using 2 years of CERES and MODIS data on Terra (Loeb et al., 2005). The same methodology is also applied to CERES measurements on Aqua. The scene identification used to develop these ADMs is based upon the cloud algorithms described in Minnis et al. (2011). TOA fluxes inverted from these ADMs and cloud properties used for scene identification are in the Edition 2 Single Scanner Footprint TOA/Surface Fluxes and Clouds (Ed2SSF) product. The overall bias in global monthly mean TOA flux from ADM uncertainties is less than $0.2 \mathrm{~W} \mathrm{~m}^{-2}$ in the SW and $0.2-$ $0.4 \mathrm{~W} \mathrm{~m}^{-2}$ in the LW (Loeb et al., 2007). However, validation studies also reveal that the uncertainties of fluxes over snow/ice are larger than those over ocean/land, and uncertainties of fluxes over clear ocean are dependent on the MODIS fine-mode fraction (Loeb et al., 2007). These findings led to this investigation to further improve the CERES ADMs.

ADMs are scene type dependent; thus accuracy in scene identification affects the characterization of anisotropy. The CERES team has improved upon the cloud algorithms used for Ed2SSF and recently delivered the improved cloud algorithms for Edition 4 SSF (Ed4SSF). The improvements in cloud algorithms include using regional mean boundary apparent lapse rates developed using collocated CALIPSO and MODIS data to determine low cloud-top height (SunMack et al., 2014); using a $\mathrm{CO}_{2}$-slicing method to retrieve high cloud over low-lying clouds (Chang et al., 2010); using a rough ice crystal model (Yang et al., 2008) to improve ice cloud retrieval; using the $1.24 \mu \mathrm{m}$ channel for cloud optical depth retrieval over snow, and other changes as discussed by Minnis et al. (2010). We utilize the improved cloud algorithm (scene identification) and all available RAP data to develop the improved next-generation CERES ADMs. This paper documents the methodology used to develop ADMs for the SW and LW (WN) channels over different scene types. The accuracy of the TOA SW, LW, and WN fluxes derived from these new ADMs will be assessed in a future publication.

\section{Observations}

CERES instruments on Terra and Aqua are flying with MODIS instruments so that the higher-resolution imager can provide cloud conditions for every CERES field of view (FOV). The CERES/MODIS cloud algorithms retrieve cloud fraction $(f$, in $\%)$, cloud optical depth, cloud phase (liquid $=1$, and ice $=2$ ), cloud top and effective temperature/pressure (among other variables) based on MODIS pixel-level measurements. These pixel-level cloud properties are spatially and temporally matched with the CERES FOV. If the cloud top pressure within a CERES FOV is significantly different, up to two non-overlapping cloud layers are defined (Loeb et al., 2003). For each cloud layer, pixel-level cloud properties are weighted by the CERES PSF to provide layer-mean cloud properties. Layer-mean cloud properties are then weighted by the layer cloud fractions to derive the cloud properties over the CERES FOV.

Other pixel-level retrievals such as aerosol optical depth and Ångström exponent from MODIS collection 5.1 (Hsu et al., 2004; Remer et al., 2008; Levy et al., 2010) are also averaged over the CERES footprints using the PSF. Similarly, spectral radiances from MODIS observations are averaged over CERES FOV weighted by the CERES PSF. These radiances are used to develop clear ocean ADMs (Sect. 4.1.1), clear land ADMs (Sect. 4.2.1), and sea ice ADMs (Sect. 4.5).

Surface elevation data are from digital elevation model GTOPO30 and resampled at a resolution of $1 / 6^{\circ}$ equal angle grid box. The elevation variability (EV) for a given grid box is calculated as the standard deviation of the elevations of this grid box and the eight surrounding grid boxes. Meteorological fields are from the Global Modeling and Assimilation Office's Goddard Earth Observing System (GEOS) version 5.4.1 data assimilation system for CERES. This version provides consistent analysis over the entire CERES data record period. Surface types are obtained from the International Geosphere Biosphere Program (IGBP) global land 
cover data set. Fresh snow and sea ice surface types are derived from a combination of the National Snow and Ice Data Center (NSIDC) microwave snow/ice map and the National Environmental Satellite, Data and Information Service (NESDIS) snow/ice map. NESDIS uses imager data to identify snow and sea ice and provide snow and sea ice information near the coast, whereas NSIDC does not provide microwave retrievals within $50 \mathrm{~km}$ of the coast. Another snow and ice data source is from the CERES team's snow and sea ice fraction over the clear portions of CERES footprints using MODIS reflectances. The presence of snow and sea ice is determined using thresholds of the reflectance at 1.6 and $0.65 \mu \mathrm{m}$, and the brightness temperature differences at 3.7 and $11 \mu \mathrm{m}$ (Minnis et al., 2008). Hereafter, we refer to this snow and sea ice fraction as cloud mask snow/ice fraction.

These cloud properties, aerosol properties, spectral radiances, meteorological data, and CERES broadband radiances are all included in the CERES Ed4SSF product. We use all available RAP data on Terra ( $\sim 60$ months) and Aqua ( $\sim 32$ months) to construct their individual ADMs over most scene types. However, over certain scene types (i.e., SW over permanent snow and sea ice, and LW over clear permanent snow, fresh snow, and sea ice) when we do not have enough samples from a single spacecraft, combined Terra and Aqua ADMs are developed.

The general strategy of constructing ADMs is to sort the measured radiances into angular bins over different scene types. Over a given scene type $(j)$, the measured radiances are sorted into discrete angular bins. Averaged radiances in all angular bins $(\hat{I})$ are calculated and all radiances in the upwelling directions are integrated to provide the ADM flux $(\hat{F})$. The ADM anisotropic factors $(R)$ for scene type $j$ are calculated as

$$
\begin{aligned}
R_{j}\left(\theta_{0}, \theta, \phi\right) & =\frac{\pi \hat{I}_{j}\left(\theta_{0}, \theta, \phi\right)}{\int_{0}^{2 \pi} \int_{0}^{\frac{\pi}{2}} \hat{I}_{j}\left(\theta_{0}, \theta, \phi\right) \cos \theta \sin \theta \mathrm{d} \theta \mathrm{d} \phi} \\
& =\frac{\pi \hat{I}_{j}\left(\theta_{0}, \theta, \phi\right)}{\hat{F}_{j}\left(\theta_{0}\right)}
\end{aligned}
$$

where $\theta_{0}$ is the solar zenith angle, $\theta$ is the CERES viewing zenith angle, and $\phi$ is the relative azimuth angle between CERES and the solar plane. For an observed radiance $\left(I_{0}\right)$ under the same scene type, it is then converted to flux by using the anisotropic factor that we derived:

$$
F\left(\theta_{0}\right)=\frac{\pi I_{\mathrm{o}}\left(\theta_{0}, \theta, \phi\right)}{R_{j}\left(\theta_{0}, \theta, \phi\right)} .
$$

Besides the sort into angular bin method for developing ADMs, we also employ analytical functions when appropriate to characterize the anisotropies over some scene types (see Sects. 4 and 5).

\section{Angular distribution model evaluation}

ADMs are sets of anisotropic factors used to convert the observed TOA radiances to fluxes. Because we do not know the instantaneous radiance angular distributions for different scene types, it is a challenging task to evaluate the ADMs that we developed. To overcome this challenge, we design an evaluation method by combining Eq. (1) with Eq. (2) to rewrite the TOA flux as

$F\left(\theta_{0}\right)=\frac{I_{\mathrm{o}}\left(\theta_{0}, \theta, \phi\right)}{\hat{I}_{j}\left(\theta_{0}, \theta, \phi\right)} \hat{F}_{j}\left(\theta_{0}\right)$.

Note that the TOA flux is sensitive to the ratio of $\hat{F}_{j}$ to $\hat{I}_{j}$, which implies that it is more important to get the shape of $\hat{I}_{j}$ correct rather than its magnitude. To facilitate the comparison between the shape of observed and ADM-predicted radiances, we first normalize the observed and predicted radiances with their own means for each $1^{\circ}$ latitude $\times 1^{\circ}$ longitude region. We then calculate the root-mean-square (rms) error between the normalized predicted radiance and the normalized observed radiance as

$\mathrm{rms}=\sqrt{\frac{1}{n} \sum_{j=1}^{n}\left(\frac{\hat{I}_{j}}{\overline{\hat{I}}}-\frac{I_{j}^{\mathrm{o}}}{\overline{I^{\mathrm{o}}}}\right)^{2}}$.

The smaller the rms error, the closer the shape of the predicted radiance to the shape of the observed radiance, which indicates the ADMs are more accurate. We use the rms error for every scene type to assess the improvement of the new ADMs we describe below. Note that this rms error is not the same as the flux rms error.

\section{Shortwave angular distribution models}

\subsection{Ocean}

\subsubsection{Clear sky}

Over ocean, clear footprints are defined as having $f<0.1 \%$. Previously, ADMs over clear ocean were developed as a function of wind speed with an angular resolution of $2^{\circ}$ in $\theta_{0}, \theta$, and $\phi$. Aerosol effects on ADMs were not explicitly considered; dependence on aerosol optical depth (AOD) is accounted for by theoretical adjustment (Loeb et al., 2005). Subsequent validation indicated that the TOA flux uncertainty depends on the MODIS AOD and fine-mode fraction (Loeb et al., 2007).

To improve the characterization of anisotropy over clear ocean, we develop new clear ocean ADMs which explicitly account for aerosols using the same angular resolution and the same wind speed bins $(0-2,2-4,4-6,6-8,8-10$, and $>10 \mathrm{~m} \mathrm{~s}^{-1}$ ). Over clear ocean, about $48 \%$ of the CERES cross-track measurements are taken when the sun glint angles are less than $40^{\circ}$ (glint region). The reflectance distributions in the glint region differ sharply from those outside 

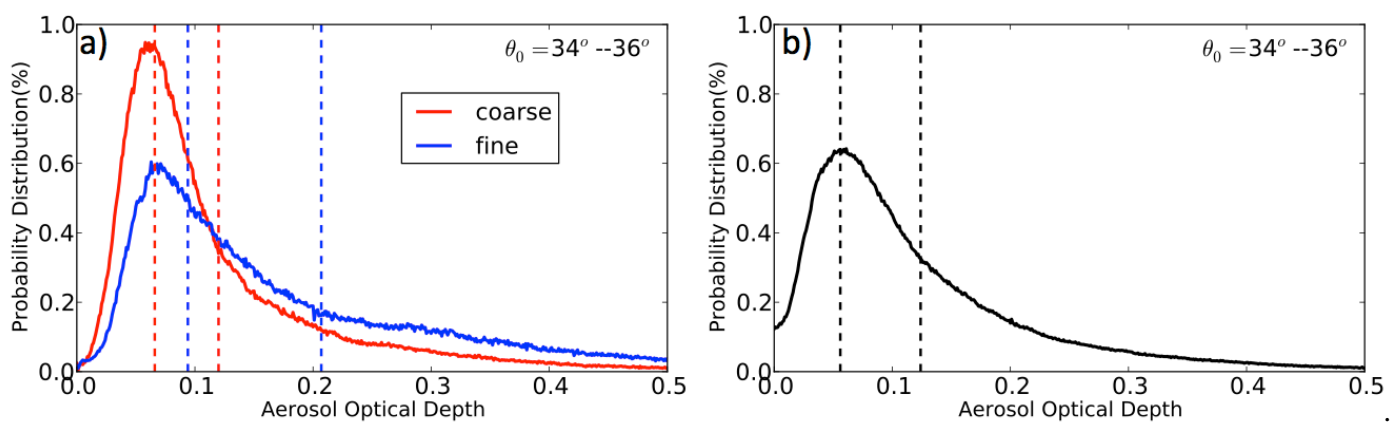

Figure 1. Probability distributions of aerosol optical depth retrieved from Ed4SSF using Terra measurements from 2000 to 2005 for $\theta_{0}=34-$ $36^{\circ}$. (a) For glint angle $>40^{\circ}$, the AOD threshold values are 0.066 and 0.12 for coarse-mode-like aerosols and are 0.094 and 0.207 for fine-mode-like aerosols. (b) For glint angle $\leq 40^{\circ}$, the AOD threshold values are 0.056 and 0.124 .

the glint region; we thus treat glint and non-glint regions separately. For the non-glint region, we develop AOD- and aerosol-type-dependent ADMs; for the glint region, we develop AOD-dependent ADMs only.

\section{Non-glint regions}

For clear footprints with glint angles greater than $40^{\circ}$, AOD and fine-mode fraction are available from the MODIS team (Remer et al., 2008). However, these retrievals are produced using a cloud mask algorithm developed by Martins et al. (2002), which is different from the cloud mask algorithm used by the CERES cloud group. Thus, not every clear CERES FOV has a MODIS aerosol retrieval (about $8.3 \%$ of the clear CERES footprints do not have valid MODIS aerosol retrievals). To ensure self-consistency, we develop an aerosol retrieval algorithm using PSF-weighted mean MODIS radiances over clear CERES footprints. This algorithm retrieves AOD based upon five-band lookup tables (LUTs) calculated using maritime tropical and urban aerosol models from Hess et al. (1998). These two aerosol models are used to represent coarse-mode-like and fine-mode-like aerosols. The LUTs are calculated for 29 AOD values ranging from 0 to 2 , and for six wind speeds (midpoints of the wind speed bins). The five MODIS bands used for aerosol retrieval are 0.47, 0.55, 0.66, 0.87 , and $1.24 \mu \mathrm{m}$ on Terra $(2.13 \mu \mathrm{m}$ on Aqua). For a given clear CERES footprint, the AOD for each aerosol model is first retrieved by minimizing the error $(\epsilon)$, which is defined as

$$
\begin{aligned}
& \epsilon_{\mathrm{c}}=\sum_{i=1}^{5}\left(\frac{\rho_{i}^{\mathrm{obs}}-\rho_{i}^{\mathrm{LUT}}\left(\mathrm{AOD}^{\mathrm{c}},|\boldsymbol{u}|\right)}{\rho_{i}^{\mathrm{obs}}+0.01}\right)^{2}, \\
& \epsilon_{\mathrm{f}}=\sum_{i=1}^{5}\left(\frac{\rho_{i}^{\mathrm{obs}}-\rho_{i}^{\mathrm{LUT}}\left(\mathrm{AOD}^{\mathrm{f}},|\boldsymbol{u}|\right)}{\rho_{i}^{\mathrm{obs}}+0.01}\right)^{2},
\end{aligned}
$$

where $\rho_{i}^{\text {obs }}$ is the MODIS observed reflectance for the $i$ th band, and $\rho_{i}^{\mathrm{LUT}}$ is the LUT reflectance calculated for different AOD and wind speed $(|\boldsymbol{u}|)$. For the coarse-mode-like
LUT, $\mathrm{AOD}^{\mathrm{c}}$ yields the smallest error $\epsilon_{\mathrm{c}}$; while for the finemode-like LUT, AOD ${ }^{\mathrm{f}}$ yields the smallest error $\epsilon_{\mathrm{f}}$. If $\epsilon_{\mathrm{c}}<\epsilon_{\mathrm{f}}$, then the aerosols of this footprint are coarse-mode-like with optical depth of $\mathrm{AOD}^{\mathrm{c}}$; otherwise they are fine-mode-like aerosols with optical depth of $\mathrm{AOD}^{\mathrm{f}}$. Our AOD retrievals exhibit very similar global distributions as those from MODIS, but are higher than MODIS AOD (not shown). For every $\theta_{0}$ bin, the distributions of fine- and coarse-mode AODs are calculated. We then divide the AODs into three groups by using AOD percentiles: less than $33 \%$ is the low-AOD bin, between 33 and $66 \%$ is the mid-AOD bin, and greater than $66 \%$ is the high-AOD bin. Figure 1a shows an example of fine- and coarse-mode AOD distributions for $\theta_{0}=34$ $36^{\circ}$, where the 33 and $66 \%$ AODs are 0.094 and 0.207 for fine-mode aerosols and 0.066 and 0.120 for coarse-model aerosols. The percentile classification approach we adopted here to construct ADMs relaxes the requirement on absolute aerosol retrieval accuracy.

For each angular bin, the observed radiances are first sorted by wind speed, then separated by aerosol type and within each type further separated into three AOD percentiles. Thus, it is possible to construct a total number of 36 (6 wind speeds, 2 aerosol types, and 3 AOD bins) ADMs over non-glint clear oceans if the observations cover all variable space. For each case, the radiances are integrated in all upwelling directions to derive the ADM fluxes, and the missing angular bins are filled with radiative transfer calculations using the same fine- and coarse-mode aerosol models mentioned above. The anisotropic factors are then derived following Eq. (1).

\section{Glint regions}

Aerosol retrievals over glint regions are difficult because of the rapid changes in reflectance and wave-slope distribution around the specular point. Thus, we expect large uncertainties in aerosol retrieval over glint region and do not think we can discriminate aerosol types. We adopt the same retrieval method as for non-glint region but only use one 

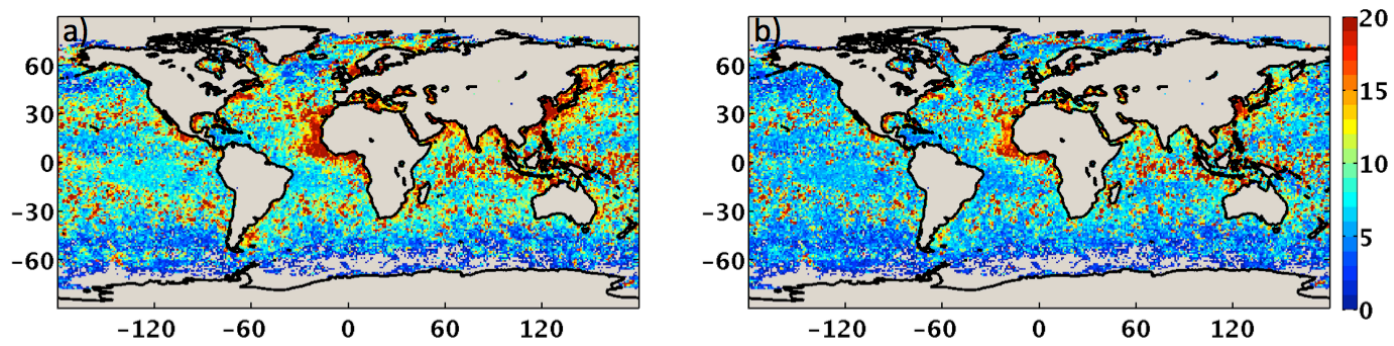

Figure 2. The rms error between normalized measured radiances and normalized ADM-predicted radiances, (a) using ADMs from Loeb et al. (2005), and (b) using the new ADMs. All clear-sky footprints from Terra RAP measurements in 2002 were used.

aerosol type (maritime tropical) and stratify the AOD distributions in each $\theta_{0}$ bin into three percentile bins (0-33, 3366 , and $66-100 \%)$. Figure $1 \mathrm{~b}$ shows the AOD distribution for $\theta_{0}=34-36^{\circ}$ bin retrieved within the glint region. Radiances taken with $\mathrm{AOD}<0.056$ are classified as the low-AOD bin, radiances taken with $0.056 \leq \mathrm{AOD}<0.124$ are classified as the mid-AOD bin, and radiances taken with $\mathrm{AOD} \geq 0.124$ are classified as the high-AOD bin. We then construct ADMs for these three AOD bins. However, reflectances over glint regions do not always monotonically increase with AOD, resulting in ambiguous retrievals. This often happens at small glint angles where specular reflectances are large. At small AOD the aerosol scattering reduces the specular reflectance from the ocean surface; then as AOD becomes large enough, the reflectance from aerosol layers starts to increase with increasing AOD. About $9 \%$ of the glint footprints produce ambiguous AOD retrievals (two AOD solutions). For these footprints, we construct ADMs without accounting for aerosols but rely on the theoretical adjustment as in Loeb et al. (2005). When a FOV is in close proximity to the specular reflection direction, we also perform a glint check by calculating the variability of the clear ocean anisotropy:

$\sigma_{R}=\left(1-f-f_{\text {ice }}\right) \sigma_{R_{\mathrm{clr}}}$

where $f$ and $f_{\text {ice }}$ are the fraction of the FOV covered by cloud and sea ice, and $\sigma_{R_{\mathrm{clr}}}$ is the standard deviation of clear ocean $R$ in the angular bins adjacent to the observation angle. If $\sigma_{R_{\mathrm{clr}}} \geq 0.05$ for a given FOV, the ADM flux $(\hat{F})$ corresponding to the FOV's scene type is used.

The aerosol-dependent ADMs characterize the clear ocean anisotropy more accurately than the ADMs developed by Loeb et al. (2005). Figure 2 shows the rms error between normalized measured radiances and ADM-predicted radiances (Eq. 4) using all clear-sky measurements of 2002 from CERES Terra RAP measurements. The global area-weighted mean rms error is $9.2 \%$ using the aerosol-dependent ADMs, whereas it is $10.9 \%$ using ADMs from Loeb et al. (2005). Significant improvements are noted over coastal regions where large amounts of dust and pollution are expected.

\subsubsection{Cloudy sky}

Over cloudy ocean, we adopt the same method as Loeb et al. (2005) to construct ADMs using an analytical function that relates CERES radiances and cloud properties retrieved from MODIS. Under cloudy conditions, the magnitude of CERES radiance in a given angular bin is most sensitive to cloud fraction $(f$, in \%), cloud optical depth $(\widetilde{\tau})$, and effective cloud phase (ECP) over the non-glint regions (glint angle $>20^{\circ}$ ) or over glint regions with sufficiently thick clouds and/or extensive cloud coverage $(\ln (f \widetilde{\tau})>6)$. Over the glint regions with $\ln (f \widetilde{\tau})<6$, ADMs are constructed using mean radiances for 6 wind speed bins (same as clear ocean) and four $\ln (f \widetilde{\tau})$ bins $(<3.5,3.5-4.5,4.5-5.5,5.5-6)$. Figure 3 shows the relationship between CERES-measured SW radiance and $\ln (f \widetilde{\tau})$ for liquid clouds in the angular bin of $\theta_{0}=44-46^{\circ}, \theta=18-20^{\circ}, \phi=88-90^{\circ}$ and for ice clouds in the angular bin of $\theta_{0}=54-56^{\circ}, \theta=14-16^{\circ}, \phi=176-178^{\circ}$ using CERES RAP measurements on Terra. The instantaneous radiances are separated into five equal sample number bins based upon $f$. The minimum and maximum cloud fractions for each bin are listed in the legend. The mean radiances for each 0.02 interval of $\ln (f \widetilde{\tau})$ are shown as black dots. We then fit the mean radiances with a five-parameter sigmoidal function:

$I=I_{0}+\frac{a}{\left[1+e^{-\left(x-x_{0}\right) / b}\right]^{c}}$,

where $x_{0}, I_{0}, a, b$, and $c$ are coefficients of the sigmoidal fit, and $x=\ln (f \widetilde{\tau})$. The sigmoidal fits over cloudy ocean are derived with an angular resolution of $2^{\circ}$ in $\theta_{0}$, $\theta, \phi$ and separately for liquid $(1.00 \leq \mathrm{ECP}<1.01)$, mixed $(1.01 \leq \mathrm{ECP} \leq 1.75)$, and ice $(1.75<\mathrm{ECP} \leq 2.00)$ clouds.

The relative rms error between the mean radiances and the fitted radiances is $3.0 \%$ for the water cloud case and $3.4 \%$ for the ice cloud case. Figure 4 shows the cumulative probability distribution of the relative rms errors between mean radiances and fitted radiances for all angular bins with $\theta_{0}$ between 10 and $80^{\circ}$ for liquid, mixed, and ice clouds. There are 86.6, 74.6, and $67.7 \%$ of the angular bins with relative rms errors less than $5 \%$, and $98.4,95.3$, and $89.3 \%$ of the angular bins with relative rms errors less than $10 \%$ for liquid, 

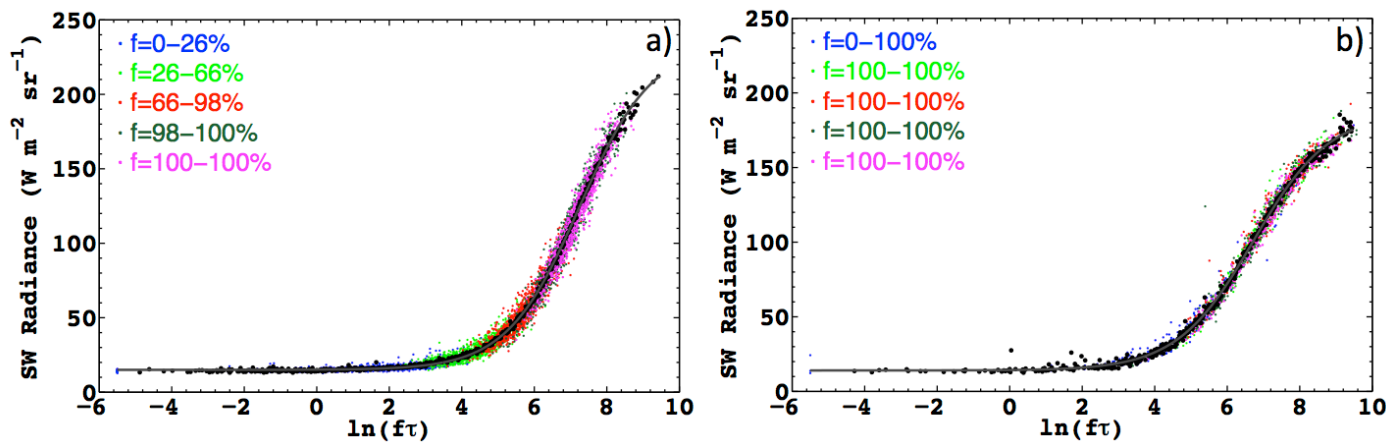

Figure 3. Relationship between SW radiances and $\ln (f \widetilde{\tau})$ over ocean using CERES Terra measurements. (a) for liquid cloud in the angular bin of $\theta_{0}=44-46^{\circ}, \theta=18-20^{\circ}$, and $\phi=88-90^{\circ}$ and (b) for ice cloud in the angular bin of $\theta_{0}=54-56^{\circ}, \theta=14-16^{\circ}$, and $\phi=176-178^{\circ}$. Colored dots are instantaneous SW radiances; black dots are mean SW radiances calculated for each 0.02 intervals of $\ln (f \widetilde{\tau})$. Black lines are the sigmoidal fits.

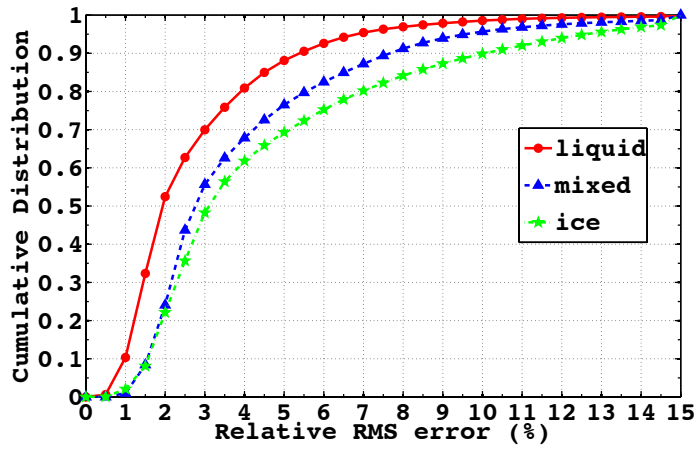

Figure 4. Cumulative distributions of the relative rms errors for the sigmoidal fits over cloudy ocean using CERES Terra measurements.

mixed, and ice clouds. The mean relative rms errors for all these angles are 3.0, 4.1, and $4.9 \%$ for liquid, mixed, and ice clouds, which are smaller than those (between 5 and 10\%) derived by Loeb et al. (2005). The reduction in relative rms errors is mostly due to the improved cloud algorithms which provide more reliable $f, \tilde{\tau}$, and cloud phase retrievals.

The TOA ADM flux in each $\ln (f \widetilde{\tau})$ interval is obtained by integrating SW radiances inferred from the sigmoidal fits in all upwelling directions. Anisotropic factors for different $\ln (f \widetilde{\tau})$ values are derived for each angular bin following Eq. (1). Figure 5 shows the anisotropy factors at $\theta_{0}=44-46^{\circ}$ in the principal plane for liquid clouds with three $\ln (f \widetilde{\tau})$ values and for different cloud phases with $\ln (f \widetilde{\tau})=6$. Anisotropy depends on the magnitude of $\ln (f \widetilde{\tau})$ and cloud phase. The liquid and mixed clouds exhibit welldefined peaks in anisotropy due to cloud glory and rainbow features, while ice clouds exhibit peaks in anisotropy in the specular reflectance direction. Cloudy scenes tend to be more isotropic as $\ln (f \widetilde{\tau})$ increases and as clouds change from liquid to ice phase.

\subsection{Land}

\subsubsection{Clear sky}

Over land, clear footprints are defined as having $f<0.1 \%$. Loeb et al. (2005) used a eight-parameter fit from Ahmad and Deering (1992) to characterize the bidirectional reflectance distribution function (BRDF) over clear land/desert. However, a kernel-based bidirectional model has proven to be effective in modeling the surface BRDF (Lucht et al., 2000; Chopping et al., 2008). Here we adopt the reciprocal RossThick-LiSparse model (Ross-Li; Roujean et al., 1992; $\mathrm{Li}$ and Strahler, 1992) to develop the reflectance over clear land/desert:

$$
\rho\left(\mu_{0}, \mu, \phi\right)=k_{0}+k_{1} \cdot B_{1}\left(\mu_{0}, \mu, \phi\right)+k_{2} \cdot B_{2}\left(\mu_{0}, \mu, \phi\right) .
$$

The first term quantifies the isotropic contribution to BRDF; the second term estimates the directional reflectance of a flat surface with randomly distributed and oriented protrusions; and the third term approximates the radiative transfer within a vegetation canopy, modified by Maignan et al. (2004) to account for the hot spot effect.

We derive the kernel weights $\left(k_{0}, k_{1}, k 2\right)$ using CERES clear-sky RAP measurements for every $1^{\circ}$ latitude by $1^{\circ}$ longitude region for each calendar month to quantify the TOA BRDF. The measured radiance in each CERES FOV is converted to a reflectance as

$\rho\left(\theta_{0}, \theta, \phi\right)=\frac{\pi I\left(\theta_{0}, \theta, \phi\right)}{\mu_{0} E_{0}}\left(1+e_{\mathrm{se}}\right)^{2}$,

where $\mu_{0}=\cos \theta_{0}, E_{0}$ is the TOA solar incoming flux $\left(1361 \mathrm{~W} \mathrm{~m}^{-2}\right)$, and $\left(1+e_{\mathrm{se}}\right)$ is the Earth-Sun distance in astronomical units. To account for the effects of solar zenith angle, vegetation coverage, and surface roughness on BRDF, the weights are derived separately for different intervals of $\mu_{0}(0.2)$, TOA normalized difference vegetation index (NDVI, 0.1), and for two categories of elevation variability $(\mathrm{EV})$ over rough terrain. A $1^{\circ} \times 1^{\circ}$ region is regarded 

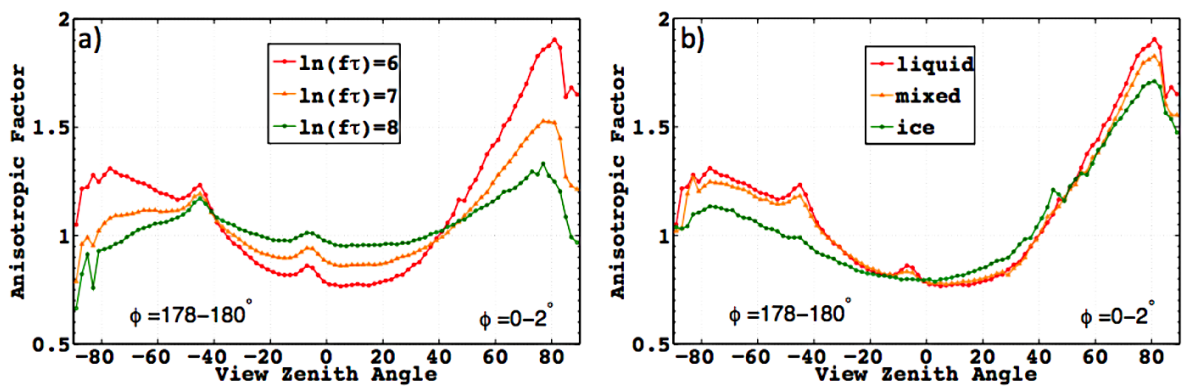

Figure 5. CERES SW anisotropic factors over ocean in the principal plane for (a) liquid clouds with different $\ln (f \tilde{\tau})$ values, (b) clouds of different phases with $\ln (f \widetilde{\tau})=6$. Anisotropic factors are derived for $\theta_{0}=44-46^{\circ}$ based upon 60 months of CERES Terra measurements.
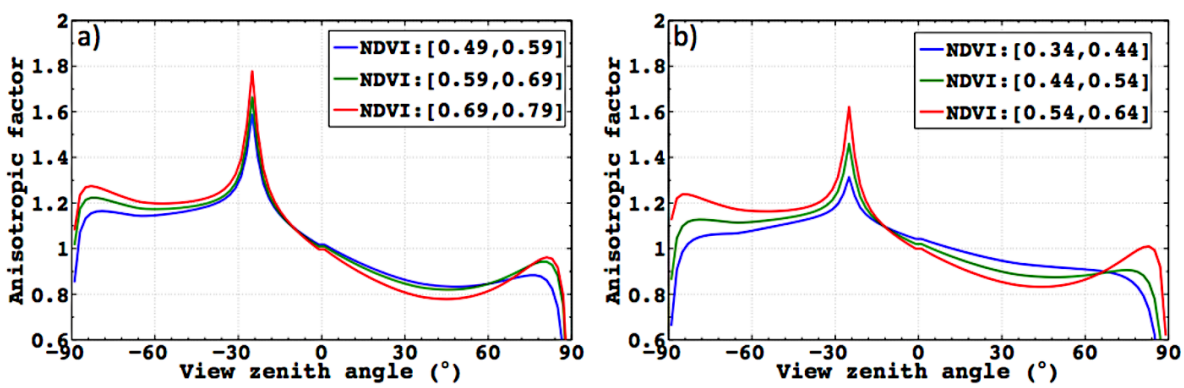

Figure 6. CERES SW anisotropic factors in the principal plane for a region centered at $6.5^{\circ} \mathrm{S}$ and $-59.5^{\circ} \mathrm{W}$ for (a) July and (b) September for $\theta_{0}=24^{\circ}$ for all available NDVI bins. Anisotropic factors are derived based upon 60 months of CERES Terra measurements over clear CERES footprints.

as rough terrain if its median $\mathrm{EV}$ is greater than $25 \mathrm{~m}$, and this region is then separated into two groups using the median EV. The TOA NDVI over clear land/desert/freshsnow CERES FOV is determined using PSF-weighted mean MODIS $0.64 \mu \mathrm{m}\left(\widetilde{I}_{0.64}\right)$ and $0.86 \mu \mathrm{m}\left(\widetilde{I}_{0.86}\right)$ radiances:

$\mathrm{NDVI}=\frac{\widetilde{I}_{0.86}-\widetilde{I}_{0.64}}{\widetilde{I}_{0.86}+\widetilde{I}_{0.64}}$

The TOA NDVI is used to separate subregions within a $1^{\circ} \times 1^{\circ}$ region that have different surface characteristics (surface type or vegetation coverage) and/or different aerosol properties. Note that the TOA NDVI is not corrected for atmospheric effect; hence it tends to decrease as aerosol optical depth increases as the aerosols are more effective scatters at $0.64 \mu \mathrm{m}$ than at $0.86 \mu \mathrm{m}$.

To construct ADMs from the BRDF fits, albedos for each $\mu_{0}$ interval in which the BRDF fit was derived are calculated by directly integrating the BRDFs. Next, a fit from Rahman et al. (1993) is used to account for the albedo dependence on solar zenith angle in each $\mu_{0}$ interval. The instantaneous anisotropic factor at a given location is derived from the ratio of reflectance to albedo for a combination of $\mu_{0}$, TOA NDVI, and $\mathrm{EV}$.

Figure 6 shows the clear-sky anisotropic factors derived from the Ross- $\mathrm{Li}$ model for a $1^{\circ} \times 1^{\circ}$ region in the Amazon $\left(6-7^{\circ} \mathrm{S}, 59-60^{\circ} \mathrm{W}\right)$ for July and September, the dry season for this location. The TOA NDVI ranges from 0.49 to 0.79 for July, but it is much lower (from 0.34 to 0.64 ) for September. The anisotropic factors are more isotropic as TOA NDVI decreases and the hot spots become less prominent. Because this region has a weak seasonality in phenology (Bradley et al., 2011), the sharp decline in TOA NDVI from July to September can not be explained solely by changes in vegetation. However, biomass burning reaches its peak in September and the aerosol optical depth is 3-4 times larger than that of July (Bevan et al., 2009), which leads to the decrease in NDVI. Figure 6 demonstrates that using NDVI to stratify the CERES measurements can provide distinctly different ADMs under different aerosol conditions, as NDVI contains combined spectral information of land surface and aerosols.

The Ross-Li model produces a more accurate characterization of anisotropy when compared to the model used by Loeb et al. (2005). Figure 7a and b show the rms error between the normalized measured radiances and the normalized predicted radiances (Eq. 4) from the two versions of ADMs using all clear-sky measurements of July 2002 from CERES Terra RAP mode. The mean rms error using the ADMs from Loeb et al. (2005) is $7.0 \%$, and it is reduced to $5.7 \%$ using the new ADMs. Significant improvements are noted over high-latitude regions. Table 1 lists the mean rms error for January, April, July, and October for 2002 CERES Terra and 2004 CERES Aqua. The new ADMs reduce the 
Table 1. The rms error (\%) between normalized measured radiances and ADM-predicted radiances over clear-sky land. Two versions of CERES ADMs are used (Loeb and New). The new ADM results are stratified into two populations by using the median aerosol optical depth $\left(\mathrm{AOD}_{\mathrm{m}}\right)$ of each $1^{\circ}$ by $1^{\circ}$ region.

\begin{tabular}{|c|c|c|c|c|c|c|c|c|}
\hline \multirow[b]{2}{*}{$\begin{array}{l}\text { ADMs } \\
\text { AOD }\end{array}$} & \multicolumn{4}{|c|}{ Terra 2002} & \multicolumn{4}{|c|}{ Aqua 2004} \\
\hline & $\begin{array}{c}\text { Loeb } \\
\text { all }\end{array}$ & $\begin{array}{c}\text { New } \\
\text { all }\end{array}$ & $\begin{aligned} & \mathrm{New} \\
< & \mathrm{AOD}_{\mathrm{m}}\end{aligned}$ & $\begin{aligned} & \text { New } \\
> & \text { AOD }_{m}\end{aligned}$ & $\begin{array}{c}\text { Loeb } \\
\text { all }\end{array}$ & $\begin{array}{c}\text { New } \\
\text { all }\end{array}$ & $\begin{aligned} & \mathrm{New} \\
< & \mathrm{AOD}_{\mathrm{m}}\end{aligned}$ & $\begin{aligned} & \text { New } \\
> & \mathrm{AOD}_{\mathrm{m}}\end{aligned}$ \\
\hline Jan & 6.7 & 6.6 & 5.8 & 5.8 & 7.2 & 5.6 & 6.5 & 6.5 \\
\hline Apr & 6.4 & 5.7 & 5.3 & 5.4 & 6.8 & 6.0 & 5.8 & 5.7 \\
\hline Jul & 7.0 & 5.7 & 5.0 & 5.2 & 7.1 & 5.8 & 5.3 & 5.3 \\
\hline Oct & 6.8 & 6.0 & 5.4 & 5.5 & 7.5 & 6.4 & 6.0 & 5.9 \\
\hline
\end{tabular}
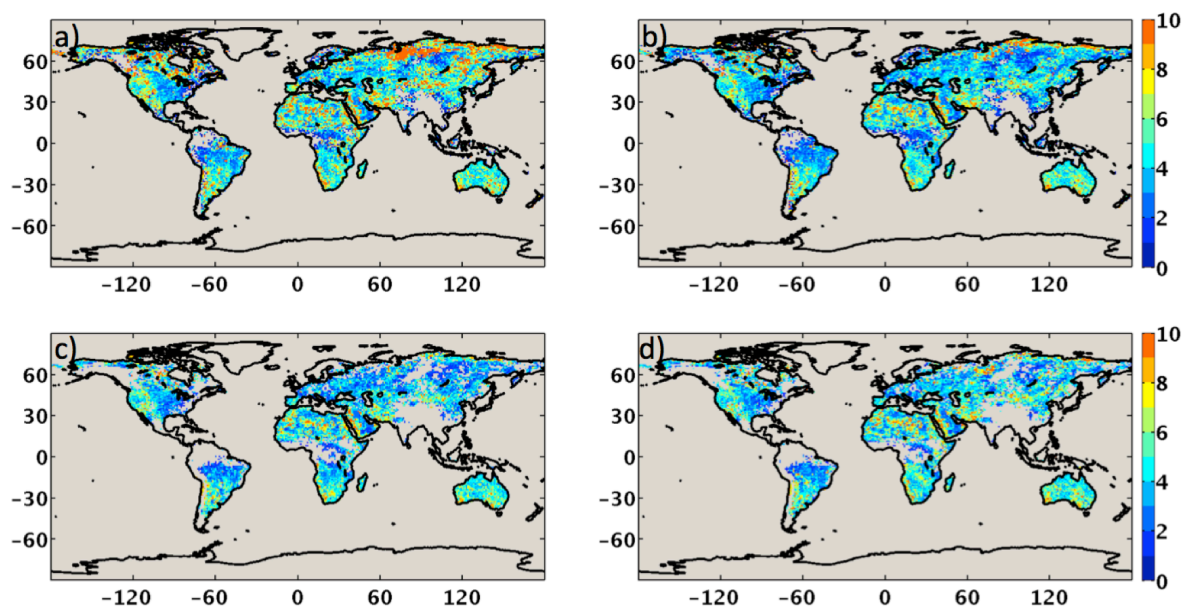

Figure 7. The rms error between normalized measured radiances and normalized ADM-predicted radiances for clear-sky land, (a) using ADMs from Loeb et al. (2005), (b) using the new ADMs, (c) using the new ADMs only for footprints with AODs less than the median AOD, and (d) using the new ADMs only for footprints with AODs greater than the median AOD.

clear-sky rms error for all seasons and large reductions occur in boreal summer and fall.

To investigate if the rms error depends on aerosol loading and type, we stratify the data in each $1^{\circ} \times 1^{\circ}$ region into two populations by using the median AOD of the region. For a given footprint, if AOD from the MODIS dark target retrieval (Levy et al., 2010) is not available we use that from the Deep Blue retrieval (Hsu et al., 2004). Note that MODIS aerosol retrievals are not available for every clear CERES footprint because different cloud mask algorithms were used. These footprints are not used in calculating the rms errors for the two aerosol populations. The rms errors for the population with AOD less than and greater than the median are shown in Fig. 7c and d, and they are almost identical. Over northwestern Africa, the median AOD exceeds 0.5 (not shown) and is predominantly dust aerosols. Over eastern China, the median AOD exceeds 0.5 and is predominantly polluted aerosols. Over Australia, the median AOD is less than 0.1. Although these regions have very different aerosol loadings and are of different types, the rms errors over these regions do not vary with aerosols. Table 1 also lists the rms errors for these two aerosol populations and they differ by less than $0.2 \%$.

\subsubsection{Cloudy sky}

Over cloudy land/desert, we adopt the same methodology as Loeb et al. (2005), which we briefly review here. The anisotropy over cloudy land/desert depends not only on cloud properties but also on the underlying surface type, especially for thin and broken cloud conditions. A similar approach as clouds over ocean (Sect. 4.1.2) is used to develop the analytical ADMs over cloudy land/desert by accounting for the contribution from the surface. The observed radiance is split into four terms:

$$
\begin{aligned}
I\left(\mu_{0}, \mu, \phi\right) & =(1-f) \frac{\mu_{0} E_{0}}{\pi} \rho^{\mathrm{clr}}\left(\mu_{0}, \mu, \phi\right)+f I^{\mathrm{cld}}\left(\mu_{0}, \mu, \phi\right) \\
& +f \frac{\mu_{0} E_{0}}{\pi}\left[\rho^{\mathrm{clr}}\left(\mu_{0}, \mu, \phi\right) e^{\frac{-\pi}{\mu_{0}}} e^{\frac{-\pi}{\mu}}\right. \\
& \left.+\bar{\alpha}^{\mathrm{clr}} \frac{t^{\mathrm{cld}}\left(\widetilde{\tau}, \mu_{0}\right) t^{\mathrm{cld}}(\tilde{\tau}, \mu)}{1-\bar{\alpha}^{\mathrm{clr}} \bar{\alpha}^{\mathrm{cld}}(\tilde{\tau})}\right]
\end{aligned}
$$

where the first and second terms represent reflection from the cloud-free and cloudy areas, and the third and fourth terms correspond to scattering by the surface and atmosphere transmitted through the clouds. Here $\rho^{\text {clr }}$ is the clear-sky 


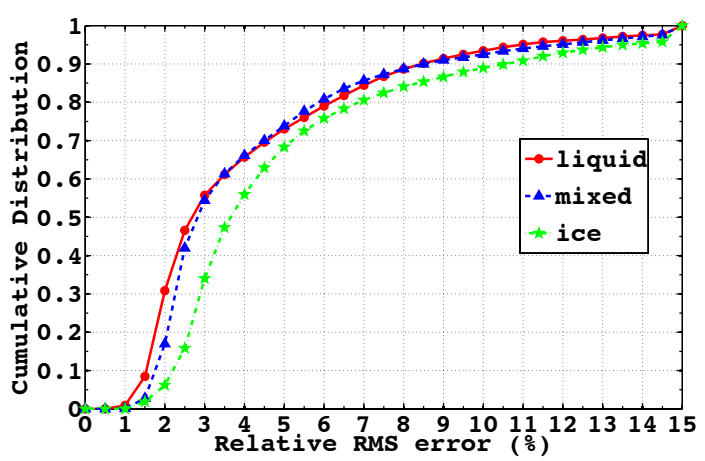

Figure 8. Cumulative distributions of the relative rms errors for the sigmoidal fits over cloudy land using CERES Terra measurements.

BRDF and $\bar{\alpha}^{\text {clr }}$ is the clear-sky spherical albedo (Thomas and Stamnes, 1999), and they are derived from $1^{\circ} \times 1^{\circ} \mathrm{BRDF}$ fits (Sect. 4.2.1); $I^{\text {cld }}$ is the radiance from the cloudy layer; $\bar{\alpha}^{\text {cld }}$ is the cloudy-sky spherical albedo and $t^{\text {cld }}$ is the diffuse transmittance of the cloud. The lookup tables of $\bar{\alpha}^{\mathrm{cld}}$ and $t^{\text {cld }}$ are generated using the broadband Langley $\mathrm{Fu}-$ Liou radiative transfer model (Fu and Liou, 1993; Rose et al., 2013).

Cloudy area contribution ( $\left.f I^{\text {cld }}\right)$ is derived from Eq. (11). The mean $f I^{\text {cld }}$ is calculated for each 0.04 interval of $\ln (f \widetilde{\tau})$ and the relationship between them is quantified using sigmoidal fit (Eq. 7) separately for liquid, mixed, and ice clouds. An angular resolution of $5^{\circ}$ in $\theta_{0}, \theta$, and $\phi$ is used for clouds over land/desert. Figure 8 shows the cumulative probability distribution of the relative rms errors between mean $f I^{\text {cld }}$ and fitted radiances for all angular bins with $\theta_{0}$ between 10 and $80^{\circ}$ for liquid, mixed, and ice clouds. There are 71.2, 72.0, and $65.8 \%$ of the angular bins with relative rms errors less than 5, and 93.0, 92.1, and $88.6 \%$ of the angular bins with relative rms errors less than $10 \%$ for liquid, mixed, and ice clouds. The mean relative rms errors for all these angles are 4.4, 4.5, and $5.4 \%$ for the three cloud phases, which are slightly larger than the rms errors over cloudy ocean.

The TOA ADM flux is computed by integrating Eq. (11) in all upwelling directions for each $\ln (f \widetilde{\tau})$ interval using SW radiances inferred from the sigmoidal fits for cloudy area and BRDF fits for clear area. Anisotropic factors for different $\ln (f \widetilde{\tau})$ values are derived for each angular bin following Eq. (1). Figure 9 shows the anisotropic factors in the principal plane for $\theta_{0}=40-45^{\circ}$ for liquid clouds with three $\ln (f \widetilde{\tau})$ values and for different cloud phases with $\ln (f \widetilde{\tau})=6$. Cloudy scenes tend to be more isotropic as $\ln (f \widetilde{\tau})$ increases and as clouds change from liquid to ice phase.

\subsection{Fresh snow}

\subsubsection{Clear sky}

Over fresh snow, clear sky is defined as footprints with $f<1 \%$. Previously clear-sky fresh-snow ADMs were devel- oped for discrete intervals of snow fractions (from the cloud mask). Because the anisotropy of fresh snow is also affected by the underlying surface type, we adopt the method that we used for clear land to account for the effect of surface type on fresh-snow anisotropy. The clear land method can be extended to fresh snow because we derive the kernel weights for each 0.1 NDVI interval. For NDVI values around 0.1 , it is likely there is snow on the ground (Hall et al., 2002). Furthermore, recent airborne measurements also indicate that the Ross-Li BRDF model is suitable over snow surfaces (Lyapustin et al., 2010).

Figure 10 shows the anisotropic factor in the principal plane for grid box centered at $49.5^{\circ} \mathrm{N}$ and $-119.5^{\circ} \mathrm{W}$ derived using all clear footprints from January measurements on Terra. There are two NDVI bins. The surface types that correspond to the low and high NDVI bins are fresh snow and evergreen needleleaf forest, respectively. The anisotropic factor for the snow-covered surface is more isotropic than snow-free surface.

\subsubsection{Cloudy sky}

The cloudy-sky fresh-snow ADMs are derived for discrete intervals of cloud fraction and snow fraction (Loeb et al., 2005; Kato and Loeb, 2005). For overcast conditions $(f>99 \%)$, the ADMs are derived separately for bright and dark surfaces and for thin $(\widetilde{\tau} \leq 10)$ and thick $(\widetilde{\tau}>10)$ clouds. A CERES FOV is determined to be bright or dark by comparing to the monthly climatological fresh-snow map. The snow map is calculated as follows: (1) determine mean MODIS $0.64 \mu \mathrm{m}$ near-nadir $\left(\theta<25^{\circ}\right)$ reflectances as a function of solar zenith angle using all clear fresh-snow CERES FOVs; (2) within a $1^{\circ}$ latitude $\times 1^{\circ}$ longitude region, if the MODIS radiances of more than $50 \%$ of CERES FOVs are greater than the mean radiances, this region is classified as bright. Otherwise, this region is classified as dark. The same method is also used to classify sea ice and permanent snow into bright and dark categories by Loeb et al. (2005) and Kato and Loeb (2005).

\subsection{Permanent snow}

\subsubsection{Clear sky}

Over permanent snow, footprints with $f<0.1 \%$ are defined as clear. Loeb et al. (2005) divided clear permanent snow footprints into dark and bright categories using the same method outlined in Sect. 4.3.2 and built corresponding ADMs. However, the surface conditions are very different between Antarctica and Greenland. The snow surface over Antarctica is covered by sastrugi because of the strong and consistent katabatic wind flow there. Sastrugi are dune-like features that are generally aligned parallel to the prevailing wind direction. They can be over a meter high (Warren et al., 1998) and thus have significant effect on snow surface BRDF 

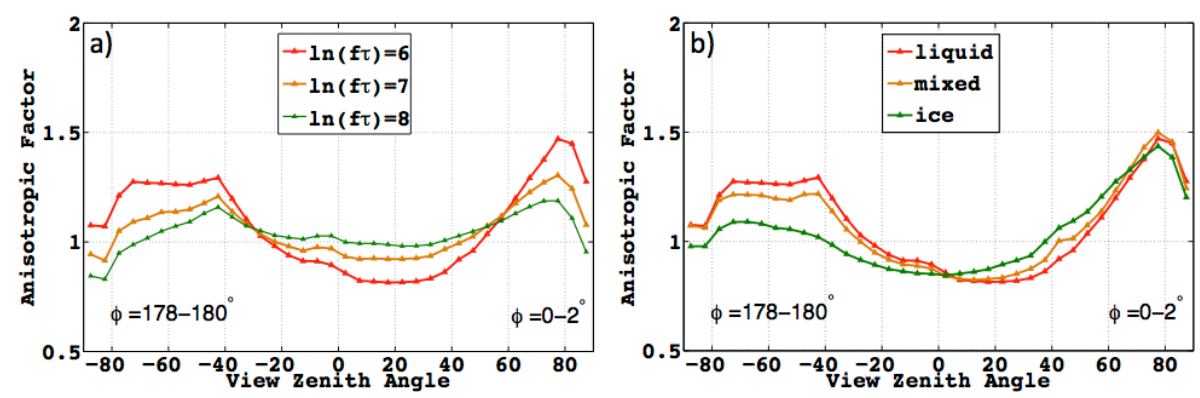

Figure 9. CERES SW anisotropic factors over land in the principal plane for (a) liquid clouds with different $\ln (f \widetilde{\tau})$ values, (b) clouds of different phases with $\ln (f \widetilde{\tau})=6$. Anisotropic factors are derived for $\theta_{0}=40-45^{\circ}$ based upon 60 months of CERES Terra measurements.
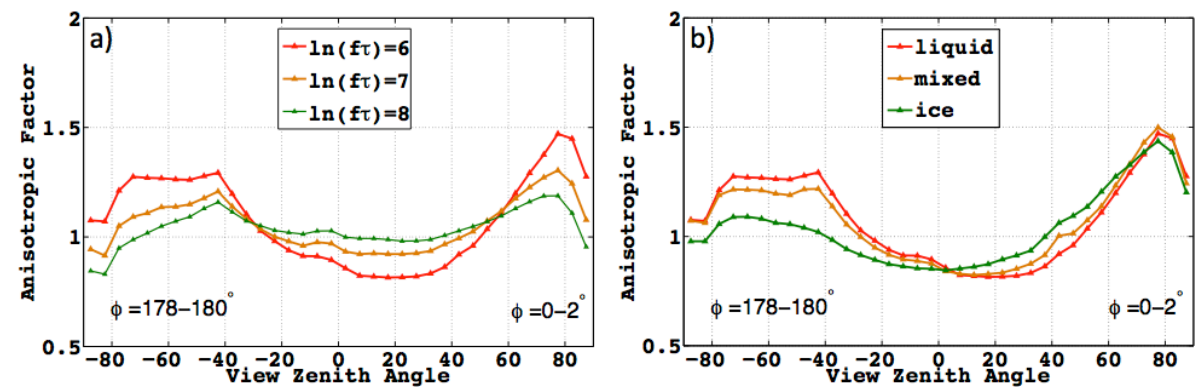

Figure 10. CERES clear-sky SW anisotropic factors in the principal plane for a region centered at $49.5^{\circ} \mathrm{N}$ and $-119.5^{\circ} \mathrm{W}$ for January for $\theta_{0}=70^{\circ}$ for all available NDVI bins. The IGBP surface type for NDVI between 0.1 and 0.2 is fresh snow and the IGBP surface type for NDVI between 0.2 and 0.3 is evergreen needleleaf forest. Anisotropic factors are derived based upon 60 months of CERES Terra measurements over clear CERES footprints.

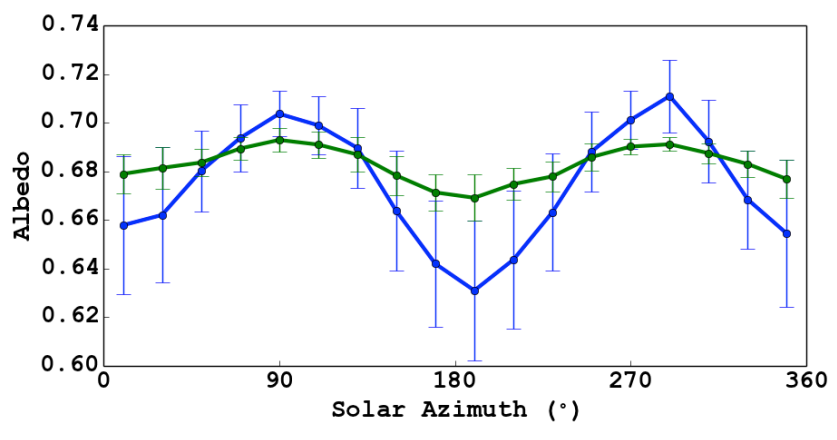

Figure 11. Mean TOA albedo and standard deviation as a function of solar azimuth angle using clear footprints in a South Pole region $\left(88-89^{\circ} \mathrm{S}\right.$, and $\left.76-83^{\circ} \mathrm{W}\right)$ during all Decembers of 2000 2004 , for $\theta_{0}=65-70^{\circ}$. The blue line shows albedos calculated using the ADMs from Loeb et al. (2005) and the green line shows albedos calculated with the new ADMs.

(e.g., Warren et al., 1998; Kuchiki et al., 2011). However, sastrugi are not found to be a noticeable feature on Greenland. To account for the differences in surface conditions, we develop separate ADMs for Antarctica and Greenland.

\section{Antarctica}

Corbett et al. (2012) demonstrated that the instantaneous albedo over clear permanent snow calculated from Ed2SSF shows a sine wave shape as solar azimuth angle changes (while $\phi$ remains within a $5^{\circ}$ bin, blue line of Fig. 11). This is because the effect that sastrugi have on the snow BRDF depends on their orientation relative to the sun. When they are aligned parallel to the sun the reflectance in the forward scattering direction is relatively high, and the back scattering reflectance is relatively low in comparison to when the sastrugi are aligned perpendicular to the sun.

To understand how sastrugi affect snow BRDF, we use measurements from the Multi-angle Imaging Spectroradiometer (MISR; Diner et al., 1998), which provides nearsimultaneous measurements of a target from nine cameras (four forward, four aftward and one nadir). These multi-angle measurements are used to quantify the effect of sastrugi on reflectances at different viewing angles, and a set of adjustment factors are developed to account for the effect of sastrugi on ADMs based upon co-located MISR and CERES measurements (Loeb et al., 2006).

We can demonstrate the effect of sastrugi over clear-sky Antarctica by examining the joint distributions of the standard scores of $0.86 \mu \mathrm{m}$ reflectances $\left(\rho_{\mathrm{m}}\right)$ from any two pairs of MISR cameras. The standard score is defined as 

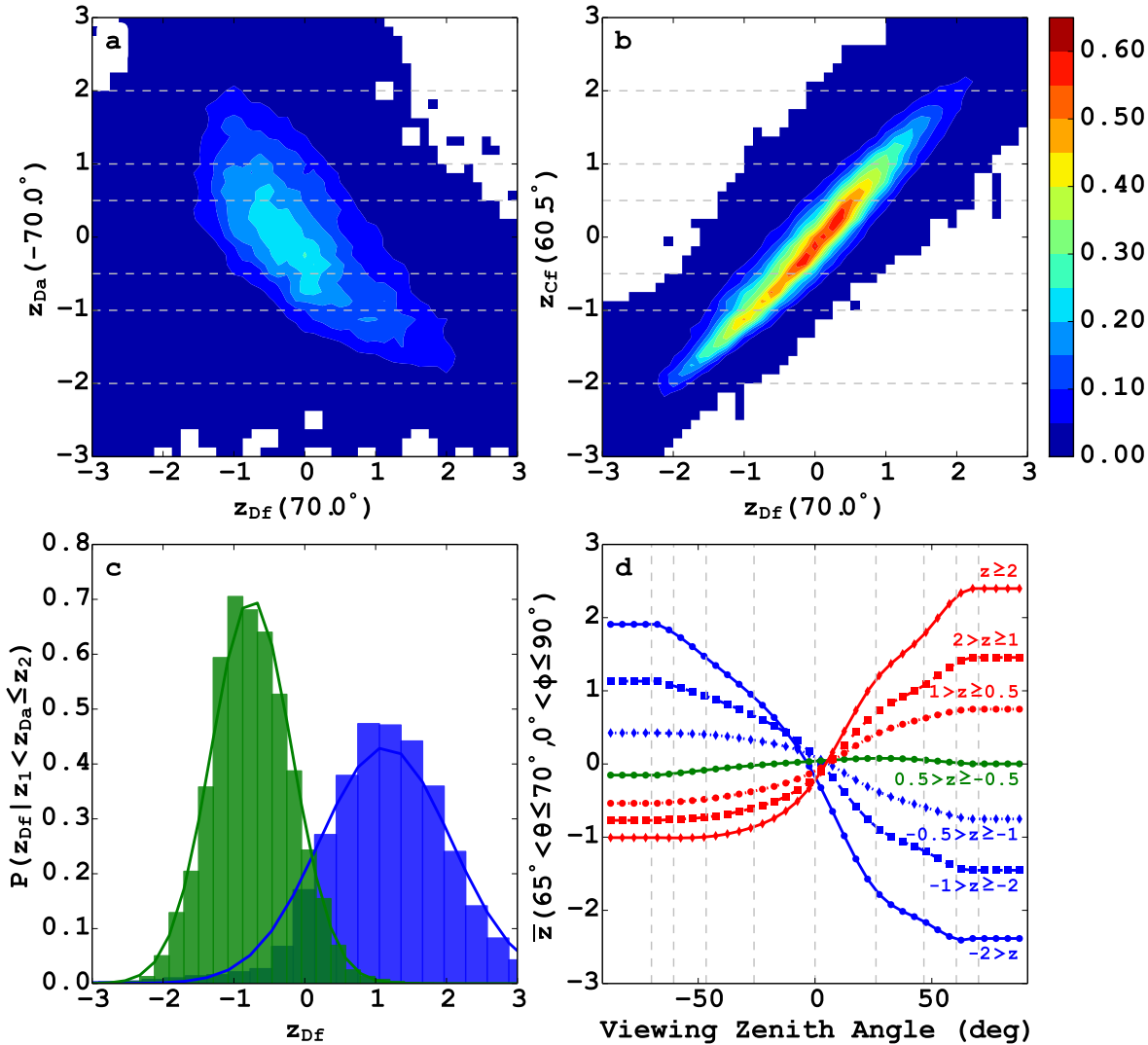

Figure 12. (a) Joint probability distribution of $0.86 \mu \mathrm{m}$ reflectance standard scores between MISR's Df and Da cameras. The dashed lines indicate the standard score ranges used to develop adjustment factors. (b) As in (a) but for MISR's Df and Cf cameras. (c) The Df conditional probabilities of standard score when the Da standard score is between -1 and -2 (blue histogram) and between 1 and 2 (green histogram). (d) Adjustment factor against viewing zenith angle for the different standard score ranges for $\theta=65-70^{\circ}$ in the forward direction. Dashed lines indicate the nine MISR camera angles. These values are used to adjust the mean CERES reflectances in order to create the ADMs.

$z\left(\theta_{0}, \theta_{\mathrm{m}}, \phi\right)=\frac{\rho_{\mathrm{m}}\left(\theta_{0}, \theta_{\mathrm{m}}, \phi\right)-\overline{\rho_{\mathrm{m}}}\left(\theta_{0}, \theta_{\mathrm{m}}, \phi\right)}{\sigma_{\rho_{\mathrm{m}}}\left(\theta_{0}, \theta_{\mathrm{m}}, \phi\right)}$,

where the averages $\left(\overline{\rho_{\mathrm{m}}}\right)$ and standard deviation $\left(\sigma_{\rho_{\mathrm{m}}}\right)$ are calculated in $5^{\circ}$ bins for all available $\theta_{0}$ and $\phi$ at each MISR viewing angle $\theta_{\mathrm{m}}$. The absolute value of $z$ represents the departure of a measurement from the mean in units of the standard deviation, with negative $z$ indicating the measurement is below the mean and positive $z$ is above the mean.

Figure 12 shows the joint distributions of $z$ between forward viewing $\operatorname{Df}\left(\theta_{\mathrm{m}}=70.5^{\circ}\right)$ camera and aftward viewing Da $\left(\theta_{\mathrm{m}}=-70.5^{\circ}\right)$ camera, and between Df camera and forward viewing $\mathrm{Cf}\left(\theta_{\mathrm{m}}=60^{\circ}\right)$ camera using all available clear-sky measurements (including multiple $\theta_{0}$ and $\phi$ bins). The two forward viewing cameras (Fig. 12b) show a strong positive correlation, but the forward and aftward cameras (Fig. 12a) show a distinct negative correlation. This indicates that the sastrugi are increasing the reflectance in one direction while at the same time decreasing the reflectance in the opposite direction. Thus, if the sastrugi cause the reflectance at a given angle to deviate from the mean by a certain amount, the joint distributions characterize how the sastrugi will affect the reflectances at other angles. We then use these to get the conditional probabilities for seven discrete intervals of $z$ (dashed lines in Fig. 12a and b), allowing us to estimate the most likely $z$ of one camera, given another camera's $z$. As $z$ does not change with $\theta_{0}$ and is only sensitive to $\phi$ being in the forward or backward direction, we average $z$ over all $\theta_{0}$ and forward and backward directions $\left(z\left(\theta_{\mathrm{m}}, \phi_{\mathrm{f} / \mathrm{b}}\right)\right)$. For example, the most likely $z$ value for the Df camera is 1.1 when $z$ is between -2 and -1 for the Da camera (blue histogram in Fig. 12c), and the most likely $z$ value for the Df camera is -0.8 when $z$ is between 1 and 2 for the Da camera (green histogram in Fig. 12c). Thus, for each MISR camera, depending on the magnitude of $z$ at this angle, we can estimate the most likely $z$ at the eight other camera angles.

These standard score relationships established using nine MISR camera angles (vertical dashed lines in Fig. 12d) are interpolated onto $5^{\circ} \theta_{\mathrm{c}}$ bins (symbols in Fig. 12d) for use with CERES measurements. For a reflectance measurement at a given $\theta$ and $\phi$, depending on how much it deviates from the mean, we can adjust the reflectances at other $\theta_{c}$ bins ac- 
cordingly. The adjustment factors also depend on $\phi$; hence they are derived separately for the forward and backward directions and are denoted as $\beta\left(\theta_{\mathrm{c}}, \phi_{\mathrm{f} / \mathrm{b}}, z\right)_{\theta, \phi}$. Figure $12 \mathrm{~d}$ shows an example of the adjustment factors for $\theta=65-70^{\circ}$ and for the forward scattering direction. The seven curves are for the seven standard score groups, and the shape of these curves indicate how much the reflectance at other viewing angles should be adjusted. If the standard score of a reflectance taken at $\theta=65-70^{\circ}$ is greater than 2, the shape of the red solid line shows how much the reflectances at other viewing angles should be adjusted. For example, the reflectance at $\theta_{\mathrm{c}}=20^{\circ}$ should be 0.7 standard deviations above the mean, and the reflectance at $\theta_{\mathrm{c}}=-50^{\circ}$ should be 1.0 standard deviations below the mean. Note that, regardless of the standard score range, the most likely value at nadir is always close to zero (no deviation from the mean reflectance). This is expected as sastrugi only have a large effect on the BRDF at oblique angles.

To construct ADMs, we first calculate the mean CERES reflectance $(\bar{\rho})$ and standard deviations $\left(\sigma_{\rho}\right)$ in $2^{\circ} \theta_{0}$ bins and $5^{\circ} \theta$ and $\phi$ bins using clear footprints over Antarctica. For each CERES $\theta$ bin, we apply the adjustment factors to $\bar{\rho}$ :

$$
\begin{aligned}
\rho_{\mathrm{a}}\left(\theta_{0}, \theta, \phi, \theta_{\mathrm{c}}, \phi_{\mathrm{f} / \mathrm{b}}, z\right) & =\bar{\rho}\left(\theta_{0}, \theta, \phi\right)+\beta\left(\theta_{\mathrm{c}}, \phi_{\mathrm{f} / \mathrm{b}}, z\right)_{\theta, \phi} \\
& \times \sigma_{\rho}\left(\theta_{0}, \theta, \phi\right),
\end{aligned}
$$

where $\rho_{\mathrm{a}}\left(\theta_{0}, \theta, \phi, \theta_{\mathrm{c}}, \phi_{\mathrm{f} / \mathrm{b}}, z\right)$ is the adjusted reflectance for a given $z$ range; if $\phi<90^{\circ}$, we pick the forward adjustment factor $\beta\left(\theta_{\mathrm{c}}, \phi_{\mathrm{f}}, z\right)_{\theta, \phi}$; otherwise we use $\beta\left(\theta, \phi_{\mathrm{b}}, z\right)_{\theta, \phi}$. These adjusted reflectances are integrated over all upwelling directions and the ADMs are derived from Eq. (1). Thus for each $\theta$ bin, we develop 14 ADMs representing how anisotropy changes as the reflectance deviates from the mean. To improve sampling, combined Terra and Aqua ADMs were developed over Antarctica as no significant differences were found over polar regions between measurements on these two spacecrafts.

For every instantaneous measurement, we need to know the standard score to selected the correct ADMs. The standard score is determined by using the mean reflectance and standard deviation calculated using all (RAP and crosstrack) CERES measurements from Terra and Aqua for each sun-satellite viewing geometry. A linear interpolation between standard score bin midpoints is used to interpolate the anisotropic factors. The new ADMs are successful in removing the albedo dependence on solar azimuth angle (green line in Fig. 11).

\section{Greenland}

Over Greenland, we create only one set of ADMs for clear sky, as we do not have enough samples to develop separate ADMs for bright and dark surfaces (Sect. 4.3.2). For the same reason, we also combined data from Terra and Aqua to develop combined ADMs. These ADMs are also applied to all non-Antarctic permanent snow scenes.

\subsubsection{Cloudy sky}

For partly cloudy scenes $(0.1 \%<f<99.9 \%)$ over permanent snow, we use the same method as Loeb et al. (2005) and Kato and Loeb (2005) to develop ADMs for discrete intervals of $f$ and adding linear interpolation between midpoints of $f$ bins. For overcast scenes $(f \geq 99.9 \%)$, we separate the footprints by ECP and $\tilde{\tau}$. We use two ECP bins $(\mathrm{ECP}<1.5$ and $\mathrm{ECP} \geq 1.5)$ and four $\tilde{\tau}$ bins $(\ln \tilde{\tau}<1$, $1 \leq \ln \tilde{\tau}<2,2 \leq \ln \tilde{\tau}<3$, and $\ln \tilde{\tau} \geq 3$ ) to construct ADMs. These $\tilde{\tau}$ bin values roughly correspond to quartiles of the overcast cloud optical depths over permanent snow. Surface brightness is not considered here. Additionally, no distinction of cloud phase is made for $\theta_{0}<60^{\circ}$ to preserve sampling. Similar to the anisotropy of clouds over ocean/land, the ice phase ADMs are more isotropic than the liquid phase ADMs over permanent snow.

\subsection{Sea ice}

The surface of sea ice is highly variable in space and time, ranging from snow-covered ice to bare ice to melt ponds. This variability in surface type affects the characterization of SW sea ice anisotropy. As there are very few data sets available that provide information about the surface conditions of the Arctic/Antarctic sea ice, one way to obtain information is through the use of spectral channels (e.g., Rösel et al., 2012; Tschudi et al., 2008). The reflectances of 0.47 and $0.86 \mu \mathrm{m}$ channels from MODIS provide large contrast for different sea ice surface types (Rösel et al., 2012), and we define the sea ice brightness index as

$\eta=1-\frac{\rho_{0.47}-\rho_{0.86}}{\rho_{0.47}+\rho_{0.86}}$.

For bright surfaces, such as snow over sea ice, $\eta$ is close to 1 as the spectrum is relatively flat between the two channels. As the snow/ice melts and melt ponds begin to form, the $0.86 \mu \mathrm{m}$ reflectance decreases faster than the $0.47 \mu \mathrm{m}$ reflectance, causing $\eta$ to decrease, with the lowest values occurring for open ocean. This is confirmed by the evolution of monthly $\eta$ maps in the Arctic region (not shown). In April, $\eta$ is high (above 0.9 over most of the Arctic oceans), as the sea ice is mostly covered by snow after the winter. As the year progresses into summer and snow/ice melts, $\eta$ starts to decrease.

\subsubsection{Clear sky}

Over sea ice, clear sky is defined as footprints with $f<1 \%$. The ADMs for clear sky are developed for six sea ice fraction (from cloud mask algorithms) bins with angular resolutions of $5^{\circ}$ for all $\theta_{0}, \theta$, and $\phi$. For scenes with sea ice fraction greater than $99 \%$, they are further divided into three $\eta$ bins (Table 2). The BRDFs of the three $\eta$ classes for $\theta_{0}=65-70^{\circ}$ are shown in Fig. 13. The lowest $\eta$ bin has the lowest albedo and highest anisotropy in its BRDF. This is what we would 
Table 2. Sea ice SW ADM scene type definitions by cloud fraction (\%), sea ice fraction (\%), sea ice brightness index $(\eta)$, cloud optical depth $(\widetilde{\tau})$, and effective cloud phase (ECP).

\begin{tabular}{|c|c|c|c|c|}
\hline $\begin{array}{l}\text { Cloud } \\
\text { fraction (\%) }\end{array}$ & $\begin{array}{l}\text { Sea ice } \\
\text { fraction }(\%)\end{array}$ & $\begin{array}{l}\text { Sea ice } \\
\text { brightness }\end{array}$ & $\begin{array}{l}\text { Cloud } \\
\text { optical depth }\end{array}$ & $\begin{array}{l}\text { Cloud } \\
\text { phase }\end{array}$ \\
\hline $0-1$ & $0-1$ & all & - & - \\
\hline \multirow[t]{5}{*}{ (clear) } & $1-25$ & all & - & - \\
\hline & $25-50$ & all & - & - \\
\hline & $50-75$ & all & - & - \\
\hline & $75-99$ & all & - & - \\
\hline & $99-100$ & $\eta \leq 0.85,0.85<\eta \leq 0.935, \eta>0.935$ & - & - \\
\hline $1-25$ & $0-1$ & all & all & all \\
\hline $25-50$ & $1-25$ & all & all & all \\
\hline \multirow{4}{*}{$50-75$} & $25-50$ & all & all & all \\
\hline & $50-75$ & all & all & all \\
\hline & $75-99$ & all & all & all \\
\hline & $99-100$ & $\eta \leq 0.85,0.85<\eta \leq 0.935, \eta>0.935$ & all & all \\
\hline \multirow[t]{6}{*}{$75-99$} & $0-1$ & all & $\ln \tilde{\tau}<1, \ln \widetilde{\tau} \geq 1$ & all \\
\hline & $1-25$ & all & $\ln \tilde{\tau}<1, \ln \tilde{\tau} \geq 1$ & all \\
\hline & $25-50$ & all & $\ln \tilde{\tau}<1, \ln \tilde{\tau} \geq 1$ & all \\
\hline & $50-75$ & all & $\ln \tilde{\tau}<1, \ln \tilde{\tau} \geq 1$ & all \\
\hline & $75-99$ & all & $\ln \tilde{\tau}<1, \ln \tilde{\tau} \geq 1$ & all \\
\hline & $99-100$ & $\eta \leq 0.85,0.85<\eta \leq 0.935, \eta>0.935$ & $\ln \tilde{\tau}<1, \ln \tilde{\tau} \geq 1$ & all \\
\hline \multirow[t]{5}{*}{ 99-100 } & all & $0-0.6$ & continuous in $\ln \tilde{\tau}$ & $\mathrm{ECP}<1.5, \mathrm{ECP} \geq 1.5$ \\
\hline & all & $0.6-0.7$ & continuous in $\ln \tilde{\tau}$ & $\mathrm{ECP}<1.5, \mathrm{ECP} \geq 1.5$ \\
\hline & all & $0.7-0.8$ & continuous in $\ln \tilde{\tau}$ & $\mathrm{ECP}<1.5, \mathrm{ECP} \geq 1.5$ \\
\hline & all & $0.8-0.9$ & continuous in $\ln \tilde{\tau}$ & $\mathrm{ECP}<1.5, \mathrm{ECP} \geq 1.5$ \\
\hline & all & $0.9-1.0$ & continuous in $\ln \tilde{\tau}$ & $\mathrm{ECP}<1.5, \mathrm{ECP} \geq 1.5$ \\
\hline
\end{tabular}

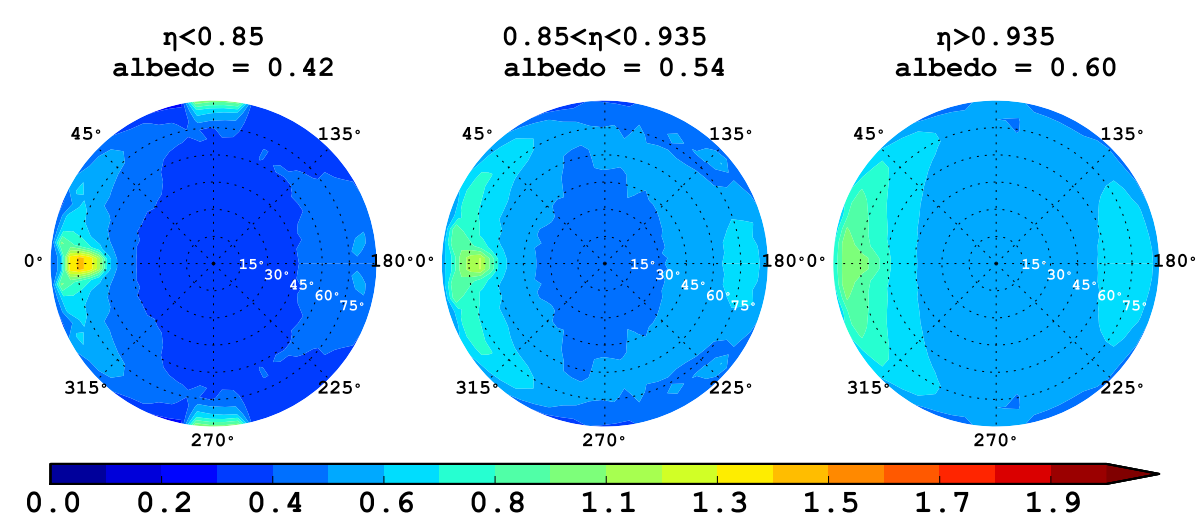

Figure 13. Clear-sky sea ice BRDFs for three $\eta$ classes for $\theta_{0}=65-70^{\circ}$.

expect, as the surface types that are being represented in this range are known to be more anisotropic than the surface represented by the higher $\eta$ bins, such as snow.

The ADMs that we developed for the high $\eta$ bin correspond well to the "bright" ADMs from Loeb et al. (2005) and Kato and Loeb (2005), while the ADMs for the low $\eta$ bin correspond well to the "dark" ADMs. The ADMs for the mid- $\eta$ bin sit between the high and low ones. The use of $\eta$ provides a measure to objectively separate the scenes into different brightness categories.

\subsubsection{Cloudy sky}

For partly cloudy scenes $(1 \leq f<99 \%)$, we use a similar approach to that of Loeb et al. (2005) and Kato and Loeb (2005). However, for partly cloudy scenes we redefine the sea ice fraction to be the fraction of the clear portion of the footprint covered by sea ice (namely, normalize the sea ice 
fraction by the clear-area fraction). Previously the sea ice fraction used was the fraction of the footprint covered by sea ice, which, as the sea ice under the clouds is unknown, could not be greater than the clear-area fraction. This redefinition increases the number of ADMs for partly cloudy scenes (Table 2) and allows us to be consistent in how we treat the clear-sky sea ice, regardless of the cloud fraction. For scenes with sea ice fraction greater than $99 \%$, we also split the scenes into three $\eta$ bins (same as clear sky). We use the PSF-weighted MODIS reflectance over clear portion of the footprint to calculate $\eta$. For scenes with $75 \leq f<99 \%$, we also construct ADMs for thin $(\ln \tilde{\tau}<1)$ and thick $(\ln \tilde{\tau} \geq 1)$ clouds.

For overcast conditions $(f \geq 99 \%)$, the new ADMs are based on a linear regression between reflectance and $\ln \tilde{\tau}$. Separate regressions are derived for liquid $(\mathrm{ECP}<1.5)$ and ice (ECP $\geq 1.5$ ) clouds, and for five $\eta$ bins (Table 2). As $\eta$ is calculated using clear MODIS pixels, we create maps of $\eta$ for each month for each $1^{\circ}$ equal angle region from clear-sky and partly cloudy footprints. Mean reflectances are calculated for each $\theta_{0}, \theta, \phi$, ECP, $\eta$, and $\ln \widetilde{\tau}$ bins. The angular resolution is $5^{\circ}$ for all three angles and the width of the $\ln \widetilde{\tau}$ bin is 1 . Linear fits are then performed between these mean reflectance values and the $\ln \widetilde{\tau}$ bin midpoints. Figure 14a shows an example of the linear regression between mean reflectance and $\ln \widetilde{\tau}$ for $\theta_{0}=55-60^{\circ}, \theta=35-40^{\circ}$, and $\phi=45-50^{\circ}$. Reflectances are larger for higher $\eta$ bins than for lower $\eta$ bins. However, once the $\ln \tilde{\tau}$ is high enough, the reflectances intersect. This suggests there is a point where the optical thickness overcomes the effect of the surface brightness.

Reflectances from linear regressions are integrated to derive albedo for different values of $\ln \tilde{\tau}$. Albedo increases linearly with $\ln \tilde{\tau}$, and a linear regression is used to represent the relationship between the albedo and $\ln \tilde{\tau}$ (Fig. 14b). For the same $\ln \tilde{\tau}$ value, albedos are higher for ice clouds than for liquid clouds, and they are also higher for larger $\eta$. Albedos and reflectances from the linear regressions are used to derive anisotropic factors.

\subsection{Mixed-scene fields of view}

For CERES FOVs that consist of multiple surface types, the SW anisotropic factors are determined by accounting for the area coverage by each surface type:

$R\left(\theta_{0}, \theta, \phi\right)=\frac{\pi\left(a_{\mathrm{W}} \hat{I}_{\mathrm{W}}+a_{\mathrm{L}} \hat{I}_{\mathrm{L}}+a_{\mathrm{S}} \hat{I}_{\mathrm{S}}\right)}{a_{\mathrm{W}} \hat{F}_{\mathrm{W}}+a_{\mathrm{L}} \hat{F}_{\mathrm{L}}+a_{\mathrm{S}} \hat{F}_{\mathrm{S}}}$,

where $a_{\mathrm{W}}, a_{\mathrm{L}}$, and $a_{\mathrm{S}}$ are the area fraction over a FOV covered by water, land, and snow/ice; $\hat{I}_{\mathrm{W}}, \hat{I}_{\mathrm{L}}$, and $\hat{I}_{\mathrm{S}}$ are the corresponding mean radiances from ADMs for the three surface types; and $\hat{F}_{\mathrm{W}}, \hat{F}_{\mathrm{L}}$, and $\hat{F}_{\mathrm{S}}$ are the corresponding ADM fluxes.
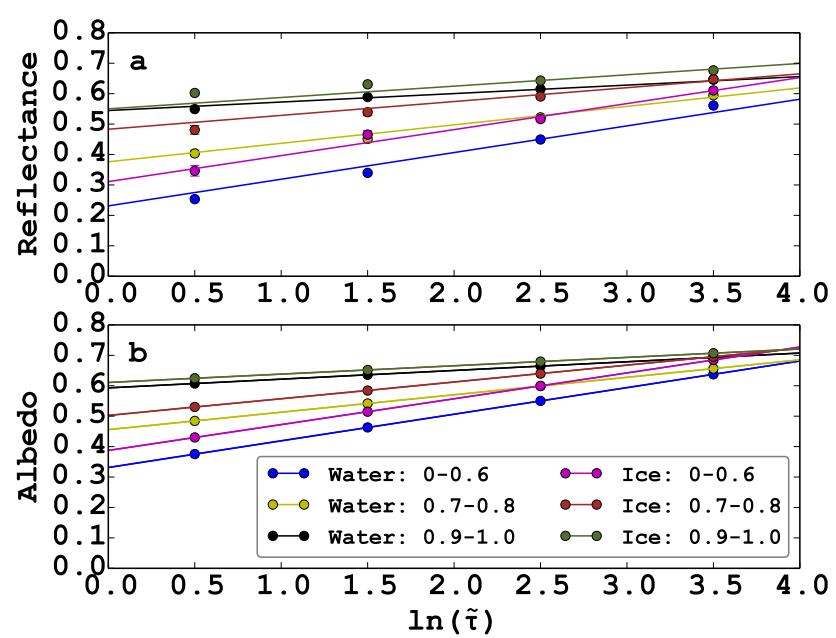

Figure 14. (a) Mean CERES reflectance values against $\ln \tilde{\tau}$ for different cloud phases and mean $\eta$ values for $\theta_{0}=55-60^{\circ}, \theta=35-$ $40^{\circ}$, and $\phi=45-50^{\circ}$. The fitted linear regression lines are also shown. (b) The albedo values against $\ln \widetilde{\tau}$ for different cloud phases and mean $\eta$ values and the fitted regressions.

\section{Longwave and window angular distribution models}

The LW/WN anisotropy is a weak function of $\theta_{0}$ and $\phi$; therefore, the LW/WN ADMs are developed only as a function of $\theta$ (with a $2^{\circ}$ angular bin resolution). Day and night ADMs are developed separately, because different cloud retrieval algorithms are used for daytime and nighttime scenes.

\subsection{Clear sky over ocean, land, and desert}

The clear-sky LW and WN ADMs are defined in terms of surface and meteorological properties. As in Loeb et al. (2005), there are six surface types (ocean, forests, savannas, grassland/cropland, dark deserts, and bright deserts). For footprints with mixed surface types, the anisotropy is calculated by averaging the ADM radiance and flux among the different types, weighted by the surface area of each type (Eq. 15). The meteorological variables used for the LW/WN ADMs are precipitable water $(w)$, lapse rate $(\Delta T)$, and surface skin temperature $\left(T_{\mathrm{S}}\right)$. The lapse rate is defined as the difference between $T_{\mathrm{S}}$ and the temperature at a level $300 \mathrm{hPa}$ below the surface pressure. The intervals for $w, \Delta T$, and $T_{\mathrm{S}}$ are listed in Table 3. Note there are now additional bins used for $T_{\mathrm{s}}$.

For clear-sky scenes, the most important variable for LW/WN anisotropy is $T_{\mathrm{s}}$, as the ADMs become more anisotropic when $T_{\mathrm{S}}$ increases. The $20 \mathrm{~K}$ interval used for $T_{\mathrm{S}}$ by Loeb et al. (2005) meant that a scene with $T_{\mathrm{s}}=291 \mathrm{~K}$ would be assumed to have the same anisotropy as one with $T_{\mathrm{S}}=309 \mathrm{~K}$. This leads to errors in predicted radiance in areas that have $T_{\mathrm{S}}$ close to the bin boundaries. To correct this, the skin temperature bin size was reduced from 20 to $10 \mathrm{~K}$, and interpolation between the $T_{\mathrm{s}}$ bins is performed when possible. The interpolation is performed in radiance space, 
Table 3. Precipitable water $(w)$, lapse rate $(\Delta T)$, and surface skin temperature $\left(T_{\mathrm{S}}\right)$ intervals used to determine LW and WN ADMs under clear-sky conditions over the ocean, land, and desert. There are $4 w$ bins, $4 \Delta T$ bins, and $10 T_{\mathrm{s}}$ bins.

\begin{tabular}{lll}
\hline$w(\mathrm{~cm})$ & $\Delta T(\mathrm{~K})$ & $T_{\mathrm{S}}(\mathrm{K})$ \\
\hline $0-1$ & $<15$ & $<260$ \\
$1-3$ & $15-30$ & $260-340$ every $10 \mathrm{~K}$ \\
$3-5$ & $30-45$ & $>340$ \\
$>5$ & $>45$ & \\
\hline
\end{tabular}

where the new anisotropic factor is calculated from a mean radiance $\hat{I}\left(w, \Delta T, T_{\mathrm{s}}\right)$ linearly interpolated between $\hat{I}(w$, $\left.\Delta T, T_{\mathrm{s}_{1}}\right)$ and $\hat{I}\left(w, \Delta T, T_{\mathrm{s}_{2}}\right)$, where $T_{\mathrm{S}_{1}}<T_{\mathrm{S}}<T_{\mathrm{s}_{2}}$. Note that, because skin temperatures are not necessarily evenly distributed within a $T_{\mathrm{S}}$ bin, the interpolation is between binaveraged values of $T_{\mathrm{s}}$. There are cases where interpolation is impossible because there is not a valid ADM above or below that of the scene's ADM. In these cases, the bin's mean ADM is used as in Loeb et al. (2005). The use of smaller $T_{\mathrm{S}}$ bins and interpolation reduces the rms error (Eq. 4) over the oceans near $30^{\circ} \mathrm{S}$, where the $T_{\mathrm{S}}$ is around $290 \mathrm{~K}$, and the global daytime monthly mean rms error is reduced from $1.7-$ 1.8 to $1.2-1.4 \%$.

We also consider additional $w$ bins, but this has very little effect on reducing the rms error. Elevation variability is also tested as an additional LW ADM variable for daytime clear land scenes, in an attempt to reduce the rms error over rough terrain. However, adding elevation variability has very little impact on the rms error.

\subsection{Clear sky over permanent snow, sea ice, and fresh snow}

The ADMs over clear permanent snow, sea ice, and fresh snow are constructed for different $T_{\mathrm{S}}$ bins (Table 4), as $T_{\mathrm{S}}$ is the most important variable for LW/WN anisotropy. The Ed4SSF produces relatively few clear-sky footprints over snow and ice surfaces, particularly at the limb. For this reason, the ADMs for these surfaces are constructed using RAP measurements from both the Terra and Aqua satellites. In cases where there were no clear footprints for a given combination of surface type, $\theta$, and $T_{\mathrm{s}}$, the mean radiance at the given $\theta$ and $T_{\mathrm{s}}$ over all snow and ice surface types (from both day and night footprints) is used. This procedure is only used for 51 out of 1485 (or $3.4 \%$ ) total $\theta$ bins, and the bins affected tend to be at the limb, where $\hat{F}$ has low sensitivity to uncertainties in radiance. Note that for mixed snow and ice surfaces, the predominant surface type is used to determine the anisotropy.

One additional factor for clear-sky anisotropy over the poles is stratospheric temperature. Over Antarctica, the surface temperature falls suddenly to approximately $215 \mathrm{~K}$ with the onset of the polar night in April, but the tem- perature at $20 \mathrm{~km}$ falls from approximately $210 \mathrm{~K}$ in April to $185 \mathrm{~K}$ in July (Hudson and Brandt, 2005). Since there is very little emission from water vapor bands for such cold atmospheres, the emission from $\mathrm{CO}_{2}$ bands in the stratosphere is the most important departure from blackbody emission, and changes in the stratospheric temperature have some impact on the anisotropy. Experiments with the Principal Component-based Radiative Transfer Model (Liu et al., 2006) using the temperature profiles from Hudson and Brandt (2005) indicate that the anisotropic factor associated with a nadir viewing zenith angle would rise from 0.995 in April to 1.002 in July. However, there is currently no stratospheric temperature information available on the SSF data product; the effect of stratospheric temperature on anisotropy will be addressed in the future.

\subsection{Cloudy sky over ocean, land, and desert}

When clouds are present over ocean, land, and desert surfaces, we adopt the same method as Loeb et al. (2005) to construct ADMs as a function of "pseudoradiance" $(\psi)$, which characterizes scenes in terms of $f, w, T_{\mathrm{s}}$, and surface-cloud temperature difference $\left(\Delta T_{\mathrm{sc}}\right)$ :

$$
\begin{aligned}
\psi\left(w, T_{\mathrm{s}}, T_{\mathrm{c}}, f, \epsilon_{\mathrm{s}}, \epsilon_{\mathrm{c}}\right) & =(1-f) \epsilon_{\mathrm{s}} B\left(T_{\mathrm{s}}\right) \\
& +\sum_{j=1}^{2}\left[\epsilon_{\mathrm{s}} B\left(T_{\mathrm{s}}\right)\left(1-\epsilon_{\mathrm{c}_{j}}\right)\right. \\
& \left.+\epsilon_{\mathrm{c}_{j}} B\left(T_{\mathrm{c}_{j}}\right)\right] f_{j},
\end{aligned}
$$

where $\epsilon_{\mathrm{s}}$ is the surface infrared emissivity, $\epsilon_{\mathrm{c}}$ is the cloud infrared emissivity, $T_{\mathrm{c}}$ is the cloud-top temperature, and $B(T)=\pi^{-1} \sigma T^{4}$ is the blackbody radiance, where $\sigma$ is the Stefan-Boltzmann constant. Subscript $j$ indicates the $j$ th cloud layer within a CERES footprint. The quantity $\epsilon_{\mathrm{c}_{j}}$ is determined according to

$\epsilon_{\mathrm{c}_{j}}=1-e^{-\tau_{\mathrm{a}_{j}}}$,

where the infrared absorption cloud optical depth of the $j$ th layer is denoted by $\tau_{\mathrm{a}_{j}}$, and is calculated according to the approach given in Minnis et al. (1998) using the visible optical depth and ice/liquid radius retrievals from the SSF product. The pseudoradiance is meant to characterize emission from the surface and cloud tops. For a given surface type, and intervals of $w, T_{\mathrm{s}}, \Delta T_{\mathrm{sc}}$, and $f$ (Table 5), the average radiance is calculated for every $1 \mathrm{~W} \mathrm{~m}^{-2} \mathrm{sr}^{-1} \psi$ bin. Separate ADMs are calculated for day and night, and for the Terra and Aqua satellites using RAP measurements. Here we increase the number of $f$ bins compared to that used by Loeb et al. (2005). This additional $f$ bin had little impact on the ADMs, but it was implemented to be consistent with the $f$ bins used for other surface types.

A more substantial change in the cloudy-sky ADMs is in the derivation of estimated radiance from pseudoradiance. 
Table 4. Surface skin temperature $\left(T_{\mathrm{S}}\right)$ intervals used to determine LW and WN ADMs under clear-sky conditions over permanent snow, sea ice, and fresh snow.

\begin{tabular}{lcc}
\hline Surface type & \multicolumn{1}{c}{$T_{\mathrm{S}}(\mathrm{K})$} & $\begin{array}{c}\text { Number of } \\
T_{\mathrm{S}} \text { bins }\end{array}$ \\
\hline Permanent snow (day) & $<210 ; 210-270$ every $10 \mathrm{~K} ;>270$ & 7 \\
Permanent snow (night) & $<210 ; 210-250$ every $10 \mathrm{~K} ;>250$ & 6 \\
Sea ice (day) & $<240 ; 240-270$ every $10 \mathrm{~K} ;>270$ & 5 \\
Sea ice (night) & $<230 ; 230-250$ every $10 \mathrm{~K} ;>250$ & 4 \\
Fresh snow (day) & $<240 ; 240-270$ every 10 K; $>270$ & 5 \\
Fresh snow (night) & $<230 ; 230-270$ every $10 \mathrm{~K} ;>270$ & 6 \\
\hline
\end{tabular}

Table 5. Surface type, precipitable water $(w)$, cloud fraction $(f)$, surface-cloud temperature difference $\left(\Delta T_{\mathrm{Sc}}\right)$, and surface skin temperature $\left(T_{\mathrm{S}}\right)$ intervals used to determine LW and WN ADMs under cloudy conditions over the ocean, land, and desert surface. There are $4 w$ bins, $5 f$ bins, $22 \Delta T_{\mathrm{sc}}$ bins, and $11 T_{\mathrm{S}}$ bins.

\begin{tabular}{lclll}
\hline Surface type & $w(\mathrm{~cm})$ & $f(\%)$ & $\Delta T_{\mathrm{sc}}(\mathrm{K})$ & $T_{\mathrm{S}}(\mathrm{K})$ \\
\hline Ocean & $0-1$ & $0.1-25$ & $<-15$ & $<275$ \\
Land & $1-3$ & $25-50$ & -15 to 85 every $5 \mathrm{~K}$ & 275 to 320 every $5 \mathrm{~K}$ \\
Desert & $3-5$ & $50-75$ & $>85$ & $>320$ \\
& $>5$ & $75-99.9$ & & \\
& & $99.9-100$ & & \\
\hline
\end{tabular}

Loeb et al. (2005) used a third-order polynomial to characterize the relationship between radiance and $\psi$. The polynomial fit can be problematic for clouds with $\Delta T_{\mathrm{sc}}>85 \mathrm{~K}$ (Fig. 15). The problems appear to arise because the polynomial is fitted to the entire range of $\psi$ for a given interval of $w, T_{\mathrm{s}}, \Delta T_{\mathrm{sc}}, f$, and $\theta$. Most of the observed clouds are at low $\psi$ values (where the observed radiance increases rapidly with $\psi$ ), while the upper part of the $\psi$ range is for optically thin clouds (where the observed radiance increases slowly with $\psi$ ). Instead of a polynomial fit, the new ADMs use the mean observed radiance $(\hat{I})$ for each $\psi$ bin, when possible. If the mean observed radiance at a given $\psi$ bin is not available, we use the polynomial fit as a backup. Examples of the mean radiance at each $\psi$ bin for three $\theta$ bins are shown in Fig. 16a for daytime ocean scenes with $w>5 \mathrm{~cm}, T_{\mathrm{s}}=300$ $305 \mathrm{~K}, \Delta T_{\mathrm{sc}}=65-70 \mathrm{~K}$, and $f=100 \%$. We see that there is a larger decrease in $\hat{I}$ with $\theta$ for higher values of $\psi$, which correspond to optically thinner clouds for a fixed $w, T_{\mathrm{s}}, \Delta T_{\mathrm{sc}}$, and $f$. The mean radiances $\hat{I}$ are calculated for each $\theta$ bin for different surface types for the intervals of $w, f, T_{\mathrm{s}}$, and $\Delta T_{\mathrm{sc}}$. These radiances are then integrated over $\theta$ to produce $\hat{F}$, and then $R$ is calculated from Eq. (1).

The anisotropic factors for $\psi=51.5$ and $99.5 \mathrm{~W} \mathrm{~m}^{-2} \mathrm{sr}^{-1}$ are shown in Fig. 16b for clouds with the same characteristics as those shown in Fig. 16a. We see that, for low $\psi$ values (thick clouds), $R$ does not change much with $\theta$ because there is little contribution from the surface, even at nadir. For high $\psi$ values (thin clouds), a significant amount of radiance from the warm ocean surface is transmitted through the cloud at nadir, but the cold cloud top dominates as $\theta$ increases. In

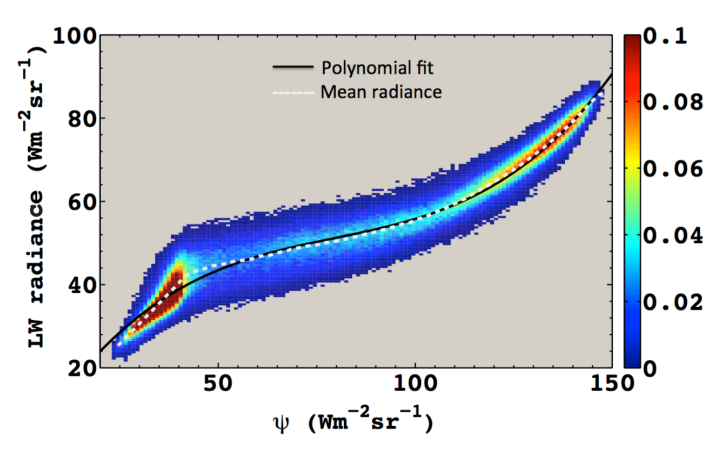

Figure 15. Observed LW radiances (contoured by percentage ) for nighttime overcast clouds over ocean surfaces with $\Delta T_{\mathrm{sc}}>85 \mathrm{~K}$, $300<T_{\mathrm{S}}<305 \mathrm{~K}, w>5 \mathrm{~cm}$, and $60^{\circ}<\theta<62^{\circ}$ plotted against pseudoradiance. Third-order polynomial fit is shown with solid black line, and mean radiance for each $1 \mathrm{Wm}^{-2} \mathrm{sr}^{-1}$ bin is shown with broken white line.

addition to the changes listed above, additional bins at higher values of $\Delta T_{\mathrm{sc}}$ were tested, but this did not have a significant effect on the retrieved fluxes.

\subsection{Cloudy sky over permanent snow, sea ice, and fresh snow}

Loeb et al. (2005) developed ADMs over snow and ice surfaces for discrete intervals of $f, T_{\mathrm{S}}$ and $\Delta T_{\mathrm{sc}}$. For the new cloudy-sky ADMs over snow and ice, we use the pseudoradiance approach that is used for cloudy-sky land, ocean, and desert (Sect. 5.3). The bin intervals of $f, T_{\mathrm{s}}$ and $\Delta T_{\mathrm{sc}}$ 
Table 6. Surface type, cloud fraction $(f)$, surface-cloud temperature difference $\left(\Delta T_{\mathrm{sc}}\right)$, and surface skin temperature $\left(T_{\mathrm{S}}\right)$ intervals used to determine LW and WN ADMs over cloudy permanent snow, sea ice, and fresh-snow surfaces. There are $5 f$ bins, $10 \Delta T_{\mathrm{Sc}}$ bins, and $8 T_{\mathrm{S}}$ bins.

\begin{tabular}{llll}
\hline Surface type & $f(\%)$ & $\Delta T_{\mathrm{sc}}(\mathrm{K})$ & $T_{\mathrm{S}}(\mathrm{K})$ \\
\hline Permanent snow & $0.1-25$ & $<-10$ & $<210$ \\
Fresh snow & $25-50$ & -10 to 70 every $10 \mathrm{~K}$ & 210 to 270 every $10 \mathrm{~K}$ \\
Sea ice & $50-75$ & $>70$ & $>270$ \\
& $75-99.9$ & & \\
& $99.9-100$ & & \\
\hline
\end{tabular}
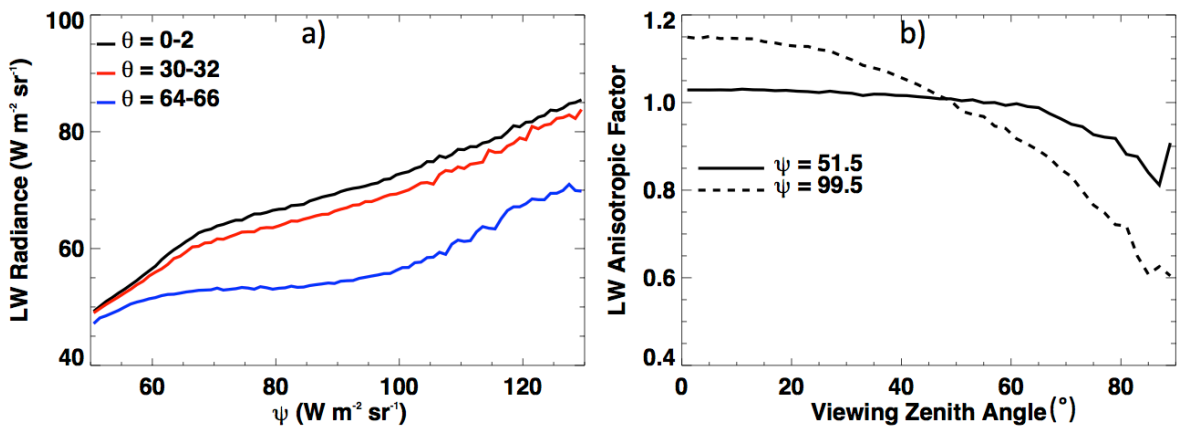

Figure 16. (a) LW radiance against $\psi$ for three $\theta$ bins over ocean for $w>5 \mathrm{~cm}, 65<\Delta T_{\mathrm{sc}}<70 \mathrm{~K}, 300<T_{\mathrm{S}}<305 \mathrm{~K}$, and $f=100 \%$. (b) $\mathrm{LW}$ anisotropic factors for $\psi=51.5 \mathrm{Wm}^{-2} \mathrm{sr}^{-1}$ and $\psi=99.5 \mathrm{Wm}^{-2} \mathrm{sr}^{-1}$.

used for snow and ice are listed in Table 6. The pseudoradiance formulation allows the LW/WN ADMs to take cloud emissivity into account (via the cloud optical depth) over permanent snow, sea ice, and fresh-snow surfaces. Variations in cloud emissivity were not considered previously, since the only cloud property used was cloud fraction. The ADMs are constructed separately for day and night, and separately for the Terra and Aqua satellites using RAP measurements. For mixed cloudy snow and ice surface types, the predominant surface type is used to determine the anisotropy.

An example of the variation of LW radiance with $\psi$ for three $\theta$ bins is shown in Fig. 17a for daytime permanent snow scenes with $T_{\mathrm{s}}=240-250 \mathrm{~K}, \Delta T_{\mathrm{sc}}=30-40 \mathrm{~K}$, and $f=100 \%$. The anisotropic factors for the same scenes are shown in Fig. 17b for $\psi=39.5$ and $51.5 \mathrm{~W} \mathrm{~m}^{-2} \mathrm{sr}^{-1}$. Here the anisotropy increases with $\psi$, although the increment with $\psi$ is smaller than that over warm surfaces (Fig. 16b). This is because the atmospheric (and associated cloud top) temperatures over polar regions tend to be closer to those at the surface than over warm oceans.

\section{Footprints with insufficient imager information}

For some CERES footprints, there is insufficient imager coverage because of missing MODIS data and/or the lack of scene identifications due to cloud property retrievals. When the total fraction of unknown cloud properties is over $35 \%$, we rely on artificial neural network (ANN) simulations to de- termine the anisotropic factors (Loukachine and Loeb, 2004). The percentage of footprints that are categorized as having insufficient imager information is greatly reduced in Ed4SSF (less than $2.0 \%$ compared to $5.6 \%$ for Ed2SSF) because of the improvement in cloud algorithms. We follow the methodology of Loukachine and Loeb (2004) and use 1 year of Terra and 1 year of Aqua RAP measurements to train the respective ANN ADMs. The instantaneous fluxes from the new ANN ADMs are validated against the fluxes inverted from the original ADMs. For SW, the rms difference between these two sets of fluxes is $5.3 \%$. For daytime LW (WN), the rms difference is about $1.0 \%(1.3 \%)$, and for nighttime LW (WN), the rms difference is $1.5 \%(1.6 \%)$. These rms differences are about half of those found in Loeb et al. (2005).

\section{Effects of scene identifications and ADMs on TOA fluxes}

TOA fluxes in Ed4SSF are different from those in Ed2SSF because of the changes in cloud algorithms and ADMs. To separate the changes in TOA fluxes caused by cloud algorithms from ADMs, we apply ADMs from Loeb et al. (2005) to the new cloud algorithms used for Ed4SSF (hereafter refer to as $\operatorname{Ed} 4 \operatorname{SSF} \beta$ ). Thus, the differences between Ed4SSF and $\operatorname{Ed} 4 \operatorname{SSF} \beta$ are due to changes in the ADMs, and differences between $\operatorname{Ed} 4 \mathrm{SSF} \beta$ and $\operatorname{Ed} 2 \mathrm{SSF}$ are due to changes in the cloud algorithms. A more stringent test for the ADM effects on flux would be updating the ADMs developed by Loeb 

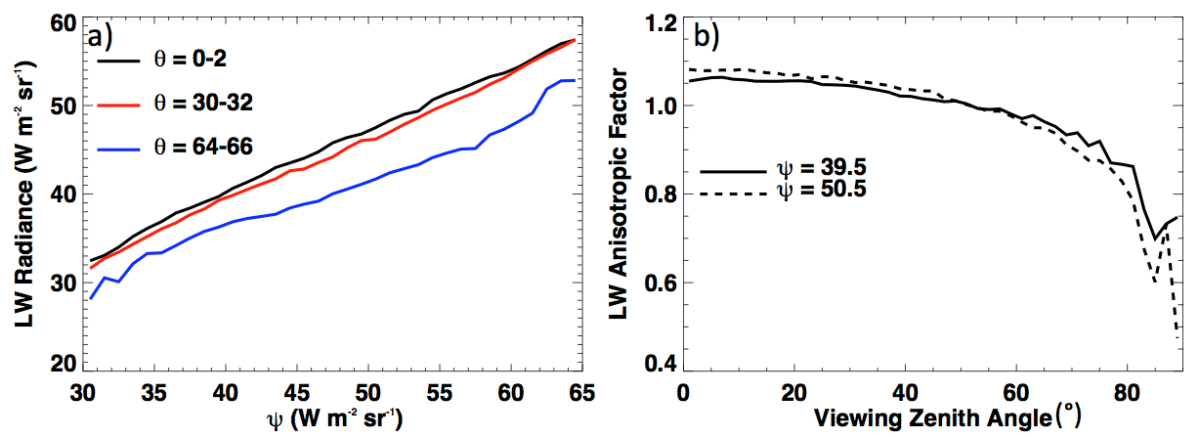

Figure 17. (a) LW radiance against $\psi$ for three $\theta$ bins over permanent snow for $30<\Delta T_{\mathrm{sc}}<40 \mathrm{~K}, 240<T_{\mathrm{S}}<250 \mathrm{~K}$, and $f=100 \%$. (b) $\mathrm{LW}$ anisotropic factors for $\psi=39.5 \mathrm{Wm}^{-2} \mathrm{sr}^{-1}$ and $\psi=50.5 \mathrm{Wm}^{-2} \mathrm{sr}^{-1}$.

Flux change caused by cloud change
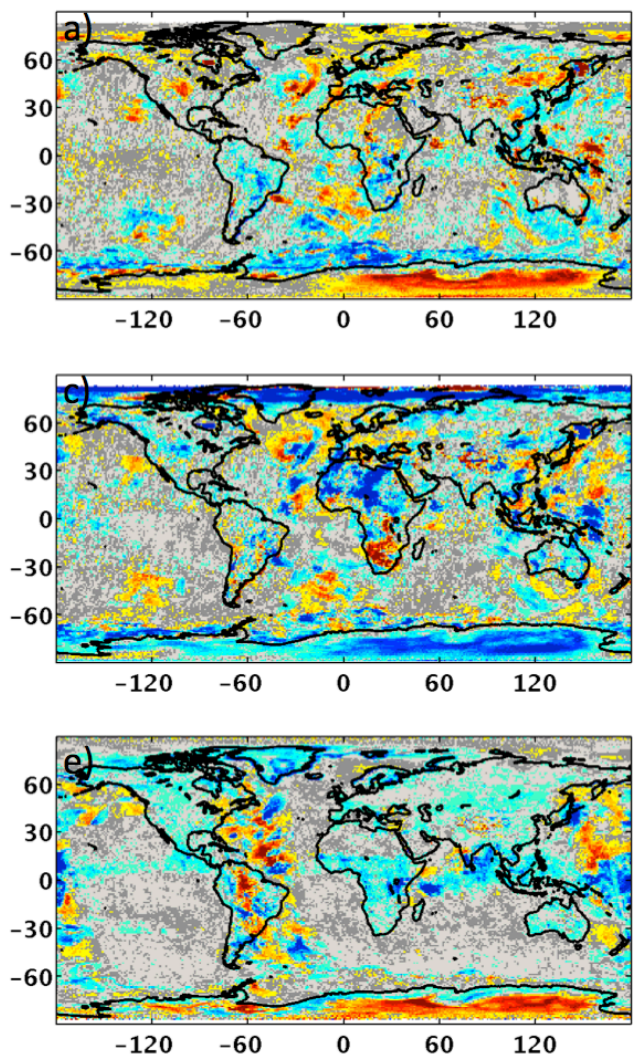

Flux change caused by ADM change
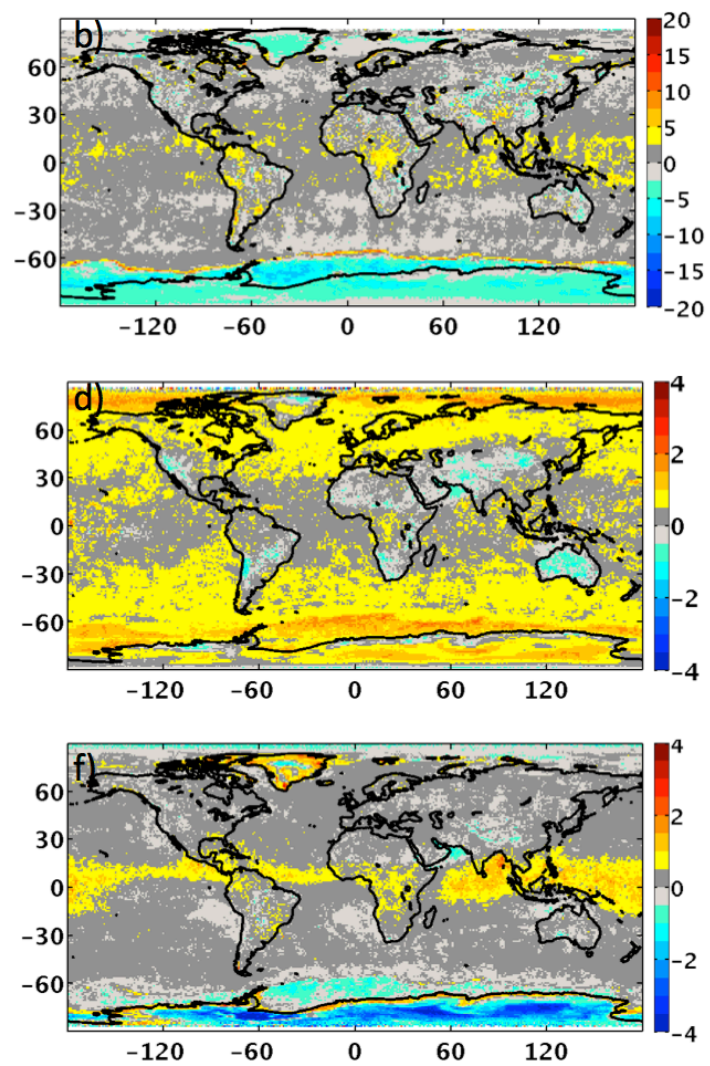

Figure 18. Instantaneous flux differences caused by changes in cloud algorithms (left panels, Ed4SSF $\beta$-Ed2SSF ) and by changes in ADMs (right panels, Ed4SSF-Ed4SSF $\beta$ ): (a) and (b) for SW, (c) and (d) for daytime LW, and (e) and (f) for nighttime LW, using Terra measurements of October 2002.

et al. (2005) with the new cloud algorithms. However, the updated ADMs were not available. The ADM effects on flux would have been expected to be slightly smaller if we had used the updated ADMs than what we present below.

Figure 18 shows the effects of cloud algorithms (left panels) and ADMs (right panels) on instantaneous monthly gridded $\left(1^{\circ} \times 1^{\circ}\right)$ TOA SW, daytime LW, and nighttime LW fluxes for October 2002 using Terra measurements. Large regional flux differences are due to changes in cloud algorithms, as the new cloud algorithms detect more clouds during both daytime and nighttime (except over Antarctica), and the clouds are also thinner (except over the polar regions during daytime) than the cloud algorithms used for Ed2SSF (Fig. 19). Additionally, because more MODIS data are available for the Ed4SSF processing and the improvement in the new cloud algorithms, there are more FOVs that provide 

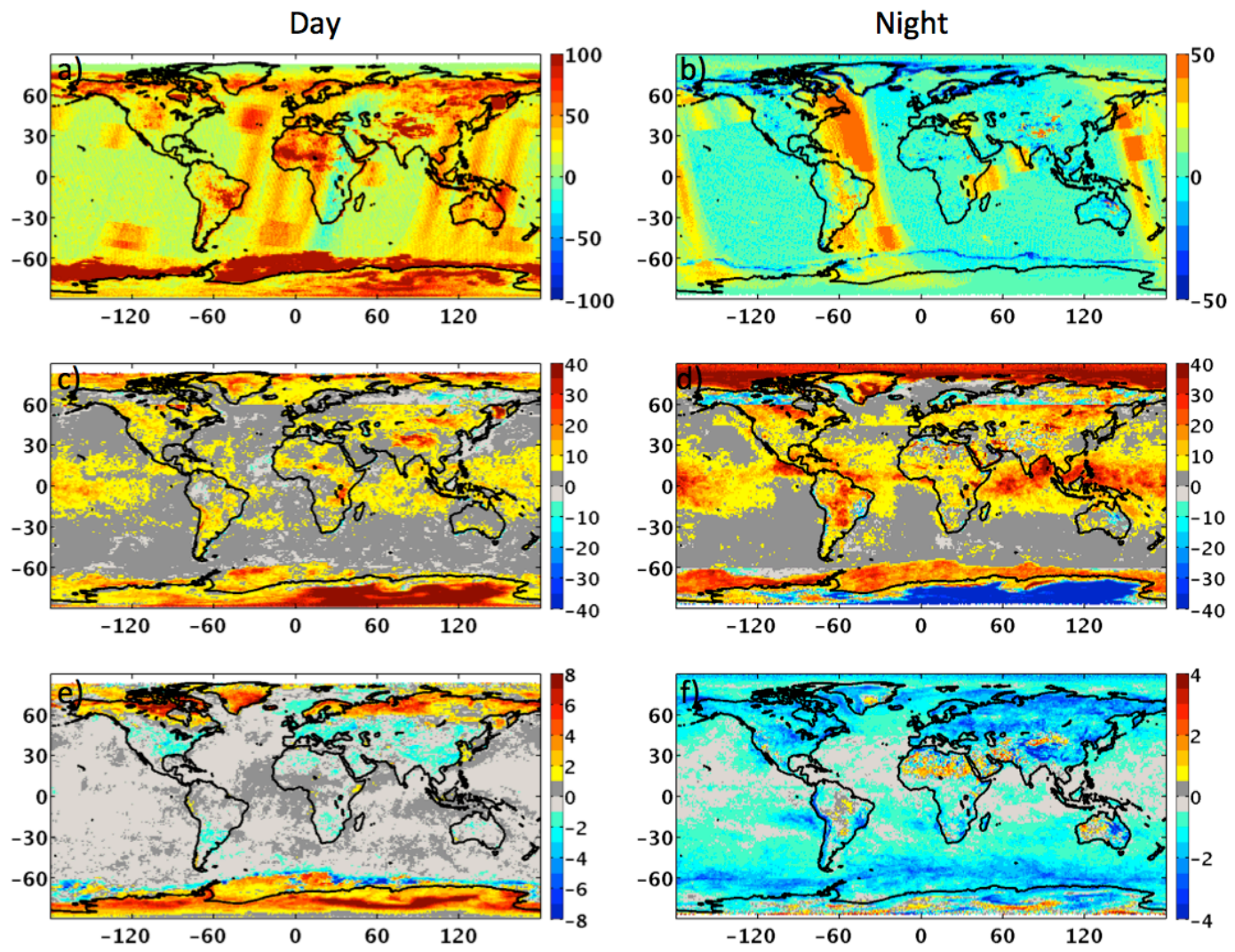

Figure 19. Daytime (right panels) and nighttime (left panels) sample number changes (a, b), cloud fraction changes (\%, c and d), and cloud optical depth changes (e, f) between Ed2SSF and Ed4SSF for each $1^{\circ}$ latitude $\times 1^{\circ}$ longitude region, using Terra measurements of October 2002.

valid flux inversions (Fig. 19a and b). Globally, the monthly mean instantaneous TOA fluxes decrease by $0.3,0.4$, and $0.3 \mathrm{~W} \mathrm{~m}^{-2}$ for $\mathrm{SW}$, daytime $\mathrm{LW}$, and nighttime $\mathrm{LW}$ between the new and old cloud algorithms. The new ADMs that we describe in this paper tend to increase the TOA SW fluxes (except over the polar regions), the daytime LW fluxes (except over some portion of the land regions), and the nighttime LW fluxes (except over the Antarctic). The global monthly mean instantaneous TOA fluxes increased by $0.6,0.4$, and $0.2 \mathrm{~W} \mathrm{~m}^{-2}$ for $\mathrm{SW}$, daytime $\mathrm{LW}$, and nighttime LW.

For monthly mean instantaneous TOA fluxes, we expect to see large differences $\left(>15 \mathrm{~W} \mathrm{~m}^{-2}\right.$ for $\mathrm{SW},>3 \mathrm{~W} \mathrm{~m}^{-2}$ for LW) on regional scales due to changes in cloud algorithms and ADMs (difference between Ed2SSF and Ed4SSF). However, differences in monthly global mean instantaneous fluxes are much smaller. For example, the monthly global mean differences for Terra 2002 range from -0.2 to $0.6 \mathrm{~W} \mathrm{~m}^{-2}$ for $\mathrm{SW}$, from -0.8 to $0.2 \mathrm{~W} \mathrm{~m}^{-2}$ for daytime $\mathrm{LW}$, and from -0.1 to $0.0 \mathrm{~W} \mathrm{~m}^{-2}$ for nighttime LW. Thus, differences in $24 \mathrm{~h}$ averaged fluxes would be even smaller than the instantaneous flux differences, especially for SW fluxes.

\section{Conclusions}

To study the Earth's radiative energy budget, the CERESmeasured SW and LW radiances must be converted to outgoing reflected SW and emitted LW fluxes at the TOA. To accomplish this conversion, we developed scene-typedependent CERES SW, LW, and WN ADMs. Scene types are determined by using surface types, cloud properties, aerosol properties, and meteorological data from GEOS-5. ADMs are derived separately for Terra and Aqua using all available CERES RAP measurements on each spacecraft for most scene types. Over some snow/ice scenes, combined Terra and Aqua ADMs are developed to improve sampling.

Over clear ocean, CERES SW ADMs over the non-glint regions are developed for six wind speed bins, three aerosol optical depth bins, and two aerosol types; and SW ADMs over the glint regions are developed without considering the aerosol types. Over clear land/desert/fresh snow, SW ADMs are developed for every $1^{\circ}$ latitude $\times 1^{\circ}$ longitude region for every calendar month using Ross-Li BRDF model. The kernels for the BRDF model are derived for different intervals of $\mu_{0}$, NDVI, and two categories of EV over rough terrain. We construct clear permanent snow ADMs separately for Antarctica and Greenland. Over Antarctica, we use MISR 
measurements to construct ADMs that account for the effects of sastrugi on anisotropy (but we do not need MISR measurements to apply the ADMs); over Greenland, we develop only one set of ADMs as sastrugi are not a noticeable feature there. Over clear sea ice scenes, the SW ADMs are developed for six sea ice fraction bins, and when sea ice fraction is greater than $99 \%$, the scenes are further divided into three sea ice brightness index bins.

Over cloudy ocean, SW ADMs are defined as continuous functions of $\ln (f \widetilde{\tau})$, where $f$ and $\tilde{\tau}$ are cloud percentage coverage and cloud optical depth derived from collocated imager pixels. The relationship between CERES-measured SW radiance and $\ln (f \widetilde{\tau})$ is quantified using a sigmoidal fit to develop ADMs, and the ADMs are derived separately for liquid, mixed, and ice phase clouds. Over cloudy land/desert, the sigmoidal fit is also used to relate the CERES SW radiance from clouds with $\ln (f \widetilde{\tau})$, by accounting for the surface anisotropy using the clear-sky ADMs. Over cloudy freshsnow surfaces, the SW ADMs are constructed for discrete intervals of cloud fraction and snow fraction; under overcast conditions, ADMs are also derived by accounting for surface brightness and cloud optical depth. Over cloudy permanent snow, the SW ADMs are constructed for discrete intervals of cloud fraction; under overcast conditions, cloud optical depth and cloud phase are also included in ADM development. Over cloudy sea ice, ADMs are developed accounting for cloud fraction, sea ice fraction and brightness; for scenes with cloud fraction greater than $75 \%$, ADMs are developed for two categories of cloud optical depth; for overcast conditions, linear regression between reflectance and $\ln \tilde{\tau}$ are used to develop ADMs for liquid and ice phase clouds under different sea ice brightness bins.

Under clear-sky conditions, the CERES LW/WN ADMs are developed for different surface types. Over land and ocean, ADMs are derived for discrete intervals of precipitable water, surface skin temperature, and lapse rate; over snow and ice surface, ADMs are derived only for discrete intervals of surface skin temperature. For cloudy conditions, the LW/WN ADMs are developed by combining surface and cloud-top temperature, surface and cloud emissivity, cloud fraction, and precipitable water (only over ocean, land, desert) into a "pseudoradiance" parameter.

The new ADMs described in this paper change the monthly mean $1^{\circ} \times 1^{\circ}$ instantaneous fluxes by less than $5 \mathrm{~W} \mathrm{~m}^{-2}$, compared to the ADMs developed by Loeb et al. (2005). However, the changes in global monthly mean instantaneous TOA fluxes are much smaller, generally less than $0.5 \mathrm{~W} \mathrm{~m}^{-2}$.

Acknowledgements. The authors thank Norman Loeb, Patrick Minnis, Sunny Sun-Mack, Walter Miller, Natividad Monalo-Smith, Constantine Lukashin, Seiji Kato, and Qing Trepte for helpful discussions.

Edited by: S. Schmid

\section{References}

Ahmad, S. P. and Deering, D. W.: A simple analytical function for bidirectional reflectance, J. Geophys. Res., 97, 18867-18886, 1992.

Bevan, S. L., North, P. R. J., Grey, W. M. F., Los, S. O., and Plummer, S. E.: Impact of atmospheric aerosol from biomass burning on Amazon dry-season drought, J. Geophys. Res., 114, D09204, doi:10.1029/2008JD011112, 2009.

Bradley, A. V., Gerard, F. F., Barbier, N., Weedon, G. P., Anderson, L. O., Huntingford, C., Aragao, L. E. O. C., Zelazowski, P., and Arai, E.: Relationships between phenology, radiation, and precipitation in the Amazon region, Global Change Biol., 17, 22452260, 2011.

Chang, F.-L., Minnis, P., Ayers, J. K., McGill, M. J., Palikonda, R., Spangenberg, D. A., Smith Jr., W. L., and Yost, C. R.: Evaluation of satellite-based upper troposphere cloud top height retrieval in multilayer cloud conditions during TC4, J. Geophys. Res., 115, D00J05, doi:10.1029/2009JD013305, 2010.

Chopping, M., Su, L., Rango, A., Martonchik, J. V., Peters, D. P. C., and Laliberte, A.: Remote sensing of woody shrub cover in desert grasslands using MISR with a geometric-optical canopy reflectance model, Remote Sens. Environ., 112, 19-34, doi:10.1016/j.rse.2006.04.023, 2008.

Corbett, J. G., Su, W., and Loeb, N. G.: Observed effects of sastrugi on CERES top-of-atmosphere clear-sky reflected shortwave flux over Antarctica, J. Geophys. Res., 117, D18104, doi:10.1029/2012JD017529, 2012.

Diner, D. J., Beckert, J. C., H.Reilly, T., Bruegge, C. J., Conel, J. E., Kahn, R. A., Martonchik, J. V., Ackerman, T. P., Davies, R., Gerstl, S. A. W., and Gordon, H. R.: Multi-angle Imaging SpectroRadiometer (MISR) instrument description an dexperiment overview, IEEE T. Geosci. Remote, 36, 1072-1087, 1998.

$\mathrm{Fu}$, Q. and Liou, K.-N.: Parameterization of the radiative properties of cirrus clouds, J. Atmos. Sci., 50, 2008-2025, 1993.

Hall, D. K., Riggs, G. A., Salomonson, V. V., DiGirolamo, N. E., and Bayr, K. J.: MODIS snow-cover products, Remote Sens. Environ., 83, 181-194, 2002.

Hess, M., Koepke, P., and Schult, I.: Optical properties of aerosols and clouds: The software package OPAC, B. Am. Meteorol. Soc., 79, 831-844, 1998.

Hsu, C., Tsay, S., King, M. D., and Herman, M.: Aerosol properties over bright-reflecting source regions, IEEE T. Geosci. Remote, 42, 557-569, 2004.

Hudson, S. R. and Brandt, R. E.: A look at the surface-based temperature inversion on the Antarctic Plateau, J. Climate, 18, 16731696., 2005.

Kato, S. and Loeb, N. G.: Top-of-atmosphere shortwave broadband observed radiance and estimated irradiance over polar regions from Clouds and the Earth's Radiant Energy System (CERES) instruments on Terra, J. Geophys. Res., 110, D07202, doi:10.1029/2004JD005308, 2005.

Kato, S., Rose, F. G., Sun-Mack, S., Miller, W. F., Chen, Y., Rutan, D. A., Stephens, G. L., Loeb, N. G., Minnis, P., Wielicki, B. A., Winker, D. M., Charlock, T. P., Stackhouse Jr., P. W., Xu, K.M., and Collins, W. D.: Improvements of top-of-atmosphere and surface irradiance computation with CALIPSO-, and MODISderived cloud and aerosol properties, J. Geophys. Res., 116, D19209, doi:10.1029/2011JD016050, 2011. 
Kuchiki, K., Aoki, T., Niwano, M., and Motoyoshi, H.: Effect of sastrugi on snow bidirectional reflectance and its application to MODIS data, J. Geophys. Res., 116, D18110, doi:10.1029/2011JD016070, 2011.

Levy, R. C., Remer, L. A., Kleidman, R. G., Mattoo, S., Ichoku, C., Kahn, R., and Eck, T. F.: Global evaluation of the Collection 5 MODIS dark-target aerosol products over land, Atmos. Chem. Phys., 10, 10399-10420, doi:10.5194/acp-10-10399-2010, 2010.

Li, X. and Strahler, A. H.: Geometric-optical bidirectional reflectance modeling of the discrete crown vegetation canopy: effect of crown shape and mutual shadowing, IEEE T. Geosci. Remote, 30, 276-292, 1992.

Liu, X., Smith, W. L., Zhou, D. K., and Larar, A.: Principal component-based radiative transfer model for hyperspectral sensors: theoretical concept, Appl. Optics, 45, 201-209, 2006.

Loeb, N. G. and Manalo-Smith, N.: Top-of-atmosphere direct radiative effect of aerosols over global oceans from merged CERES and MODIS observations, J. Climate, 18, 3506-3526, 2005.

Loeb, N. G. and Schuster, G. L.: An observational study of the relationship between cloud, aerosol and meteorology in broken low-level cloud conditions, J. Geophys. Res., 113, D14214, doi:10.1029/2007JD009763, 2008.

Loeb, N. G., Manalo-Smith, N., Kato, S., Miller, W. F., Gupta, S. K., Minnis, P., and Wielicki, B. A.: Angular Distribution Models for Top-of-Atmosphere Radiative Flux Estimation from the Clouds and the Earth's Radiant Energy System Instrument on the Tropical Rainfall Measuring Mission Satellite, Part I: Methodology, J. Appl. Meteorol., 42, 240-265, 2003.

Loeb, N. G., Kato, S., Loukachine, K., and Manalo-Smith, N.: Angular Distribution Models for Top-of-Atmosphere Radiative Flux Estimation from the Clouds and the Earth's Radiant Energy System Instrument on the Terra Satellite, Part I: Methodology, J. Atmos. Ocean. Tech., 22, 338-351, 2005.

Loeb, N. G., Sun, M., Miller, W. F., Loukachine, K., and Davies, R.: Fusion of CERES, MISR, and MODIS measurements for topof-atmosphere radiative flux validation, J. Geophys. Res., 111, D18209, doi:10.1029/2006JD007146, 2006.

Loeb, N. G., Kato, S., Loukachine, K., Manalo-Smith, N., and Doelling, D. R.: Angular Distribution Models for Top-ofAtmosphere Radiative Flux Estimation from the Clouds and the Earth's Radiant Energy System Instrument on the Terra Satellite, Part II: Validation, J. Atmos. Ocean. Tech., 24, 564-584, 2007.

Loeb, N. G., Lyman, J. M., Johnson, G. C., Allan, R. P., Doelling, D. R., Wong, T., Soden, B. J., and Stephens, G. L.: Observed changes in top-of-the-atmosphere radiation and upper-ocean heating consistent within uncertainty, Nat. Geosci., 5, 110-113, doi:10.1038/NGEO1375, 2012.

Loukachine, K. and Loeb, N. G.: Top-of-atmosphere flux retrievals from CERES using artifical neural networks, Remote Sens. Environ., 93, 381-390, 2004.

Lucht, W., Schaaf, C. B., and Strahler, A. H.: An anogorithm for the retrieval of albedo from space using semiempirical BRDF models, IEEE T. Geosci. Remote, 38, 977-998, 2000.

Lyapustin, A., Gatebe, C. K., Kahn, R., Brandt, R., Redemann, J., Russell, P., King, M. D., Pedersen, C. A., Gerland, S., Poudyal, R., Marshak, A., Wang, Y., Schaaf, C., Hall, D., and Kokhanovsky, A.: Analysis of snow bidirectional reflectance from ARCTAS Spring-2008 Campaign, Atmos. Chem. Phys., 10, 4359-4375, doi:10.5194/acp-10-4359-2010, 2010.
Maignan, F., Breon, F.-M., and Lacaze, R.: Bidirectional reflectance of Earth targets: Evaluation of analytical models using a large set of spaceborne measurements with emphasis on the hot spot, Remote Sens. Environ., 90, 210-220, 2004.

Martins, J. V., Tanre, D., Remer, L. A., Kaufman, J. Y., Mattoo, S., and Levy, R.: MODIS cloud screening for remote sensing of aerosols over oceans using spatial variability, Geophys. Res. Lett., 29, 1619-1622, 2002.

Minnis, P., Garber, D. P., Young, D. F., Arduini, R. F., and Takano, Y.: Parameterizations of reflectance and effective emittance for satellite remote sensing of cloud properties, J. Atmos. Sci., 55, 3313-3339, 1998.

Minnis, P., Trepte, C. R., Sun-Mack, S., Chen, Y., Doelling, D. R., Young, D. F., Spangenberg, D. A., Miller, W. F., Wielicki, B. A., Brown, R. R., Gibson, S. C., and Geier, E. B.: Cloud detection in nonpolar regions for CERES using TRMM VIRS and TERRA and AQUA MODIS data, IEEE T. Geosci. Remote, 46, 38573884, 2008.

Minnis, P., Sun-Mack, S., Trepte, Q. Z., Chang, F.-L., Heck, P. W., Chen, Y., Yi, Y., Arduini, R. F., Ayers, K., Bedka, K., Bedka, S., and Brown, R.: CERES Edition 3 Cloud Retrievals, in: 13th Conference on Atmospheric Radiation, Am. Meteorol. Soc., Oregon, Portland, 2010.

Minnis, P., Sun-Mack, S., Young, D. F., Heck, P. W., Garber, D. P., Chen, Y., Spangenberg, D. A., Arduini, R. F., Trepte, Q. Z., Smith, W. L. J., Ayers, J. K., Gibson, S. C., Miller, W. F., Chakrapani, V., Takano, Y., Liou, K., and Xie, Y.: CERES Edition-2 cloud property retrievals using TRMM VIRS and TERRA and AQUA MODIS data, Part I: Algorithms, IEEE T. Geosci. Remote, 49, 4374-4400, doi:10.1109/TGRS.2011.2144601, 2011.

Pincus, R., Batstone, C. P., Hofmann, R. J. P., Taylor, K. E., and Glecker, P. J.: Evaluating the present-day simulation of clouds, precipitation, and radiation in climate models, J. Geophys. Res., 113, D14209, doi:10.1029/2007JD009334, 2008.

Quaas, J., Boucher, O., Bellouin, N., and Kinne, S.: Satellite-based estimate of the direct and indirect aerosol climate forcing, J. Geophys. Res., 113, D05204, doi:10.1029/2007JD008962, 2008.

Rahman, H., Pinty, B., and Verstraete, M. M.: Coupled surfaceatmosphere reflectance (CSAR) model 2. Semiempirical surface model usable with NOAA Advanced Very High Resolution Radiometer data, J. Geophys. Res., 98, 20,791-20,801, 1993.

Remer, L. A., Kleidman, R. G., Levy, R. C., Kaufman, Y. J., Tanre, D., Mattoo, S., Martins, J. V., Ichoku, C., Koren, I., $\mathrm{Yu}$, H., and Holben, B.: Global aerosol climatology from the MODIS satellite sensors, J. Geophys. Res., 113, D14S07, doi:10.1029/2007JD009661, 2008.

Rose, F. G., Rutan, D. A., Charlock, T. P., Smith, G. L., and Kato, S.: An algorithm for the constraining of radiative transfer calculations to CERES-observed broadband top-ofatmosphere irradiance, J. Atmos. Ocean. Tech., 30, 1091-1106, doi:10.1175/JTECH-D-12-00058.1, 2013.

Rösel, A., Kaleschke, L., and Birnbaum, G.: Melt ponds on Arctic sea ice determined from MODIS satellite data using an artificial neural network, The Cryosphere, 6, 431-446, doi:10.5194/tc-6431-2012, 2012.

Roujean, J.-L., Leroy, M., and Deschamps, P.-Y.: A bidirectional reflectance model of the Earth's surface for the correction of remote sensing data, J. Geophys. Res., 97, 20455-20468, 1992. 
Satheesh, S. K. and Ramanathan, V.: Large differences in tropcial aerosol forcing at the top of the atmosphere and Earth's surface, Nature, 405, 60-63, 2000.

Smith, G. L.: Effects of time response on the point spread function of a scanning radiometer, Appl. Optics, 33, 7031-7037, 1994.

Smith, G. L., Green, R. N., Raschke, E., Avis, L. M., Suttles, J. T., Wielicki, B. A., and Davies, R.: Inversion methods for satellite studies of the Earth's radiation budget: development of algorithms for the ERBE mission, Rev. Geophys., 24, 407-421, 1986.

Stephens, G. L., Li, J.-L., Wild, M., Clayson, C. A., Loeb, N. G., Kato, S., L'Ecuyer, T., Stackhouse., P. W., Lebsock, M., and Andrews, T.: An update on Earth's energy balance in light of the latest global observations, Nat. Geosci., 5, 691-696, doi:10.1038/NGEO1580, 2012.

Su, W., Bodas-Salcedo, A., Xu, K.-M., and Charlock, T. P.: Comparison of the tropical radiative flux and cloud radiative effect profiles in a climate model with Clouds and the Earth's Radiant Energy System (CERES) data, J. Geophys. Res., 115, D01105, doi:10.1029/2009JD012490, 2010a.

Su, W., Loeb, N. G., Xu, K., Schuster, G. L., and Eitzen, Z. A.: An estimate of aerosol indirect effect from satellite measurements with concurrent meteorological analysis, J. Geophys. Res., 115, D18219, doi:10.1029/2010JD013948, 2010b.

Su, W., Loeb, N. G., Schuster, G. L., Chin, M., and Rose, F. G.: Global all-sky shortwave direct radiative forcing of anthropogenic aerosols from combined satellite observations and GOCART simulations, J. Geophys. Res., 118, 1-15, doi:10.1029/2012JD018294, 2013.

Sun-Mack, S., Minnis, P., Chen, Y., Kato, S., Yi, Y., Gibson, S. C., Heck, P. W., and Winker, D. M.: Regional apparent boundary layer lapse rates determined from CALIPSO and MODIS data fro cloud height determination, J. Appl. Meteorol. Clim., 53, 9901011, doi:10.1175/JAMC-D-13-081.1, 2014.

Suttles, J. T., Green, R. N., Minnis, P., Smith, G. L., Staylor, W. F., Wielicki, B. A., Walker, I. J., Young, D. F., Taylor, V. R., and Stowe, L. L.: Angular radiation models for Earth-atmosphere system, Vol. I, Shortwave radiation, NASA RP-1184, Tech. rep., NASA Langley Research Center, Hampton, Virginia, 1988.
Thomas, G. E. and Stamnes, K.: Radiative Transfer in the Atmosphere and Ocean, Cambridge University Press, 1999.

Trenberth, K. E., Fasullo, J. T., and Kiehl, J.: Earth's global energy budget, B. Am. Meteorol. Soc., 90, 311-323, doi:10.1175/2008BAMS2634.1, 2009.

Tschudi, M., Maslanik, J., and Perovich, D.: Derivation of melt pond coverage on Arctic sea ice using MODIS observations, Remote Sens. Environ., 112, 2605-2614, 2008.

Wang, H. and $\mathrm{Su}, \mathrm{W}$. : Evaluating and understanding top of the atmosphere cloud radiative effects in Intergovernmental Panel on Climate Change (IPCC) fifth assessment report (AR5) cloupled model intercomparison project phase 5 (CMIP5) models using satellite observations, J. Geophys. Res., 118, 1-17, doi:10.1029/2012JD018619, 2013.

Warren, S., Brandt, R., and Hinton, P.: Effect of surface roughness on bidirectional reflectance of Antarctic snow, J. Geophys. Res., 103, 25789-25807, 1998.

Wielicki, B. A., Barkstrom, B. R., Harrison, E. F., Lee, R. B., Smith, G. L., and Cooper, J. E.: Clouds and the Earth's Radiant Energy System (CERES): An Earth Observing System Experiment, B. Am. Meteorol. Soc., 77, 853-868, 1996.

Wild, M., Folini, D., Schar, C., Loeb, N. G., Dutton, E. G., and Konig-Langlo, G.: The global energy balance from a surface perspective, Clim. Dynam., 40, 3107-3134, doi:10.1007/s00382012-1569-8, 2013.

Yang, P., Kattawar, G. W., Hong, G., Minnis, P., and Hu, Y.: Uncertainties associated with the surface texture of ice particles in satellite-based retrieval of cirrus clouds - Part I: single-scattering properties of ice crystals with surface roughness, IEEE T. Geosci. Remote, 46, 1940-1947, 2008.

Zhang, J., Christopher, S. A., Remer, L. A., and Kaufman, Y. J.: Shortwave aerosol radiative forcing over cloud-free oceans from Terra: 2. Seasonal and global distributions, J. Geophys. Res., 110, D10S24, doi:10.1029/2004JD005009, 2005. 